\title{
Impact of urbanization on the simulation of extreme rainfall in the city
} of Jeddah, Saudi Arabia

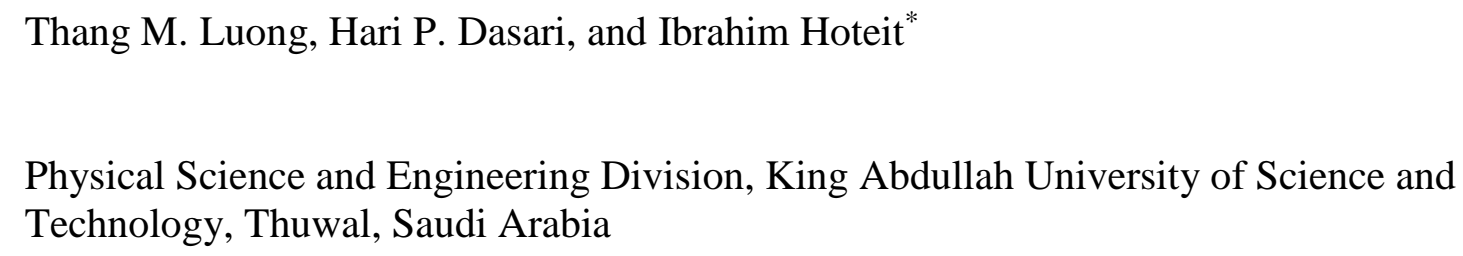

Early Online Release: This preliminary version has been accepted for publication in Journal of Applied Meteorology and Climatology, may be fully cited, and has been assigned DOI 10.1175/JAMC-D-19-0257.1. The final typeset copyedited article will replace the EOR at the above DOI when it is published. 


\section{Abstract}

48 The city of Jeddah, Kingdom of Saudi Arabia is characterized by a hot and arid

49 desert climate. Occasionally, however, extreme precipitation events have led to flooding

50 that caused extensive damage in human life and infrastructure. This study investigates the

51 effect of incorporating an urban canopy model and urban land cover when simulating

52 severe weather events over Jeddah using the Weather Research and Forecasting (WRF)

53 model at a convective-permitting scale $(1.5-\mathrm{km}$ resolution). Two experiments were

54 conducted for 10 heavy rainfall events associated with the dominant large-scale patterns

55 favoring convection over Jeddah: (i) an "urban" experiment included the urban canopy

56 model and modern-day land cover, and (ii) a "desert" experiment replaced the city area

57 with its pre-settlement, natural land cover. The results suggest that urbanization plays an

58 important role in modifying rainfall around city area. The "urban" experiment enhances

59 the amount of rainfall by $26 \%$ on average over the Jeddah city area comparing to the "desert"

60 experiment in these extreme events. The changes in model-simulated precipitation are

61 primarily tied to a nocturnal heat island effect that modifies the planetary boundary layer

62 and atmospheric instability of the convective events. 


\section{1. Background and Motivation}

64 Mesoscale convective systems associated with strong moisture convergence ahead of an

65 upper-level trough that merged with the Red Sea Trough (RST) were suggested to be the

66 dominant patterns behind the formation and intensification of the extreme precipitation

67 events in Jeddah, Saudi Arabia (Dasari et al. 2018; Deng et al. 2015). The complex

68 geographical features of the region, such as the Hijaz Mountains to the East of the city, and

69 a land-sea boundary to the West further enhance low-level moisture convergence and

70 convection activities. Under specific synoptic conditions, the orographic effect occurs on

71 the windward side of the mountain ranges and may trigger strong and rapid rainfall bursts

72 from convective storms (Haggag and El-Badry 2013). The runoffs due to intense rainfall

73 from the desert foothills generate surface flow toward the city and sometimes significant

74 flood damages.

75 The city of Jeddah has witnessed bursting urbanization and population growth over

76 the past three decades, during which it has almost tripled in size. This resulted in an overall

77 land surface cover change from natural desert-type to areas of urban development

78 (Alqurashi and Kumar 2016). Large metropolitan regions in the middle of deserts, which

79 occupy about a thousand square kilometers in geographic space, modify their surrounding

80 environment in a variety of ways (Bornstein and LeRoy 1990). Changes in land use/land

81 cover alter the surface energy and moisture exchanges with the atmosphere and thus the

82 thermodynamic characteristics of the planetary boundary layer. The increase in surface

83 roughness due to the presence of buildings and urban structures mechanically increases

84 turbulence downwind and generates upward vertical motion (Bornstein and LeRoy 1990;

85 Diem and Brown 2003). 
The best-recognized modification effect of cities on their surrounding environment

87 is that urbanized surfaces reduce albedo and absorb more incoming solar radiation, which

88 is then converted to sensible heat. In large cities surrounded by highly vegetated natural

89 landscapes, like forests and croplands, the city would then tend to become a "heat island."

90 Higher surface temperatures and deeper planetary boundary layers (PBL) are typical

91 conditions over a city, as compared to the surrounding rural areas (Rozoff et al. 2003).

92 It has been well documented in cities located in the central and eastern United States

93 that a deeper PBL in association with the urban "heat island" causes low-level convergence

94 favorable for the enhancement of convective precipitation downwind of the city (Bornstein

95 and Lin 2000; Cotton and Pielke 2007; Rozoff et al. 2003). Numerous case studies have

96 been conducted based on modeling sensitivity experiments and observational analyses, as

97 for instance for New York City, New York (Bornstein and LeRoy 1990); Atlanta, Georgia

98 (Bornstein and Lin 2000; Shem and Shepherd 2009); St. Louis, Missouri (Rozoff et al.

99 2003); Chicago, Illinois (Changnon 2001); Houston, Texas (Burian and Shepherd 2005;

100 Orville et al. 2001; Shepherd et al. 2010); and Oklahoma City (Hand and Shepherd 2009).

101 Urbanization was documented to increase the precipitation leeward of the urban

102 area and to decrease it in the area further inland in the coastal city of Tokyo (Kusaka et al.

103 2019; Kusaka et al. 2014). Horizontal divergence and moisture convergence are the

104 triggering mechanisms of thunderstorms in another coastal city of Sydney (Gero and

105 Pitman 2006). The presence of urban areas in other coastal cities in the tropic such as

106 Jakarta and Kuala Lumpur enhances precipitation due to an intensification of the diurnal

107 cycle (Argueso et al. 2016). Comparatively, much less is known about how anthropogenic

108 land-use change affects convective precipitation in a coastal-desert city like Jeddah, 
109 especially in terms of numerical atmospheric modeling, where model sensitivity

110 experiments were conducted with respect to changes to land use/land cover classifications.

111 Increases in moisture, instability, and precipitation during the winter months in

112 Jeddah are associated with the Red Sea Trough (RST), a northward extension of the

113 southern Red Sea low-pressure system at lower atmospheric levels (de Vries et al. 2013).

114 The large-scale features are important regional factors that produce extreme precipitation,

115 which for a particular case, may exceed three times the average annual rainfall. During

116 such events, a short quasi-stationary mesoscale convective system (MCS) often produces

117 severe weather with heavy precipitation and flash flooding (de Vries et al. 2016; Deng et

118 al. 2015; Yesubabu et al. 2016). Impact of urbanization on thunderstorm development and

119 evolution in the Jeddah area is yet to be revealed when these extreme events occur during

120 the winter season.

121 Precipitation in the city of Jeddah is generated by thunderstorms on the mesoscale

122 and is intimately linked to the diurnal cycle of heating of terrain and generation of

123 mountain-valley circulations (Diem and Brown 2003). Synoptic-scale features, as for

124 instance transient inverted troughs, facilitate quasi-geostrophic upward vertical motion and

125 provide favorable wind shear profiles for convective organization and propagation

126 (Lahmers et al. 2016). Under these types of conditions, organized convection, in the form

127 of MCSs and squall lines, may propagate into the Jeddah area. Convective propagation is

128 made possible through successive outflow boundaries, or cold pools, from leading

129 convective lines. The outflow boundaries mechanically lift moist and unstable air, which

130 trigger more convection (Corfidi 2003). The resultant MCSs may well sustain into the 131 morning hours. 
132 The question of interest in this study is: Does the aforementioned heat island in

133 Jeddah locally affect the thunderstorms? The influence of urbanization on severe

134 thunderstorms over the region is, as yet, poorly understood. Our main objective is to

135 evaluate how changes in land use/land cover in the Jeddah urban area could impact severe

136 thunderstorm events, and if so to explain the physical mechanisms behind them.

\section{2. Analysis and Methods}

138 a. Experiments strategy

139 Ten severe weather events were simulated in numerical weather prediction (NWP) mode

140 with a convection-permitting regional atmospheric model. The strategy for simulating and

141 evaluating the results is as follows. We focused on and analyzed in details the event of the

1422009 flood (Yesubabu et al. 2016), which is one of the most severe and well-documented

143 weather event that occurred in the Jeddah area. We retrospectively modeled it following a

144 short-term, numerical weather forecast-type mode, based on two simulations accounting

145 for desert and urban land use/land cover: one desert with no urban scheme and one city

146 with urban scheme. This specific event is described in more details in the next subsection.

147 We evaluated both simulations in details as an idealized case study, in the context of the

148 changes in model-simulated precipitation and their physical causes. Another set of nine

149 rainfall events were conducted following the same strategy for a total of ten extreme events

150 to assess the general physical mechanisms of urbanization impact on precipitation. These

151 ten events were selected as they are all active Red Sea trough cases, and associated with

152 similar synoptic/mesoscale features with strong tropical-extratropical interactions.

153 b. Summary of the severe weather event on 25-26 November 2009 
154 One of the most severe weather events that occurred over the Jeddah region over a period 155 of approximately 24 hours on 25 and 26 November, 2009 was selected as an idealized test

156 case. During the storm event, the Presidency of Meteorology and Environment (PME)

157 surface observatory at King Abdulaziz International (KAI) Airport in Jeddah recorded

158 accumulated rainfall of $140 \mathrm{~mm}$ between $0600 \mathrm{UTC}$ and 1200 UTC. The synoptic

159 meteorological conditions of the event have been well described by (de Vries et al. 2016;

160 Yesubabu et al. 2016), and are summarized below.

161 Prior to the event, a northward extension of the RST and intensification of the

162 Arabian Anticyclone (AA) provided warm moist air to the region, creating favorable

163 conditions for the development of an extreme weather event. Later, the intrusion of a mid-

164 latitude upper-level trough genereated cyclonic flow and cold air advection, and the 165 intensification of the subtropical jet due to midlatitude forcing enhanced the upper-level

166 divergence that triggered the event. The rainfall was fueled by enhanced moisture transport

167 from the Red Sea, and upward motions resulted predominantly from tropospheric

168 instability. The configuration of the AA and upper trough allowed moist airflow to

169 converge over the Jeddah region, producing what could be described as a quasi-stationary

170 MCS (Haggag and El-Badry 2013). The event resulted in an estimated damage of about 1

171 billion USD (de Vries et al. 2013), and the attendant flash flooding caused 161 fatalities.

172 c. Convection-permitting regional atmospheric simulations

173 Convection-permitting modeling is essential for the proper representation of precipitation

174 extremes and organized convective structures (Kendon et al. 2017; Prein et al. 2015),

175 particularly over desert areas (Luong et al. 2018; Luong et al. 2017). Model simulations

176 have also been demonstrated to be more successful at simulating heavy rainfall over the 
177 Jeddah area at high resolution and without using a convective parameterization scheme

178 (Deng et al. 2015; Yesubabu et al. 2016). Convection-permitting simulations were

179 therefore performed to achieve the best model performance, as described below.

180 The Weather Research and Forecast (WRF) model version 3.9 (Skamarock et al.

181 2008) was used to generate the convection-permitting simulations over the Jeddah region.

182 Lateral boundary forcing was obtained from the European Centre for Medium-Range 183 Weather Forecasts (ECMWF) interim reanalysis (ERA-Interim) dataset (Dee et al. 2011).

184 The model was used to produce short-term numerical weather forecast-type simulations of

18536 hours duration from 1200 UTC of the previous day to 0000 UTC of the next day, with

186 a twelve-hour model spin-up period. The first twelve hours of the simulation is considered

187 as the model spin-up period and therefore was not included when calculating total 188 precipitation or studying the model behavior. We produced a total of ten 36-hour 189 simulations for each experiment. The dates as well as rainfall characteristics of the ten 190 cases are summarized in Table 1. Meteorological outputs are saved every hour.

191 A three-domain one-way nesting strategy was implemented with a coarse domain 192 of $22.5-\mathrm{km}$ grid spacing (d01), an intermediate domain of 4.5-km grid spacing (d02), and 193 a convection-permitting domain of $1.5-\mathrm{km}$ grid spacing (d03). The model grid structure is 194 shown in Fig. 1 with the city of Jeddah located in the center of the third domain.

195 The physical parameterizations used in these WRF model simulations are 196 consistent over all three domains. These include the Predicted Particle Property scheme for 197 microphysics (Morrison and Milbrandt 2015), the Mellor-Yamada-Janjic planetary 198 boundary layer scheme (Janjic 1994), the RRTMG shortwave and longwave schemes 199 (Iacono et al. 2008), the unified Noah land surface model (LSM) (Tewari et al. 2004), and 
200 the Eta similarity scheme for the surface layer (Janjic 2002; Janjic 1994; Monin and 201 Obukhov 1954). We also used the one-layer Urban Canopy Model (UCM) (Chen et al. 202 2011; Kusaka and Kimura 2004; Kusaka et al. 2001) within the Noah land surface model, 203 which was applied over those areas where the land use tiling was defined as URBAN in

204 Fig. 2a. The urban land use tiles were then replaced with the natural desert land cover in 205 the DESERT simulation, as outlined in Fig. 2b. The "barren or sparsely vegetated" landuse 206 was selected for the DESERT experiment because Jeddah is built within a desert with very 207 sparse vegetation. Anthropogenic heating was not included in the UCM.

208 d. Land surface scenario sensitivity experiments

209 In the WRF model, the Noah UCM and LSM were applied to a fraction of the model grid 210 cells with built and natural surfaces, respectively. The Noah UCM considers urban 211 geometry in the surface energy balance and momentum flux calculations (Chen et al. 2011).

212 We applied the UCM over all cities defined as urban in the region in the third domain at $213 \quad 1.5-\mathrm{km}$ resolution.

214 Two land surface scenarios were considered in the two model sensitivity 215 experiments that were conducted for the 10 rainfall events: (i) an urbanized scenario with 216 the current land coverage of the region (referred to as the URBAN simulation), and (ii) a 217 pre-settlement scenario with natural landscape (referred to as the DESERT simulation). 218 The two simulations were analyzed and compared to evaluate salient differences.

219 The default 21-class MODIS land-use data of WRF version 3.9 has been used to 220 identify urban grid points. The value of the urban fraction is fixed and the urban 221 morphology parameters (e.g. urban fraction, anthropogenic heat, surface albedo, roughness 222 length for momentum over roof, ground or building, roof height) are specified from lookup 
223 table URBPARM.TBL. The urban dataset is of circa 2001. The specific values of the urban

224 parameters are outlined in Table 2. The results of extensive simulations that we have

225 conducted in several previous studies, using the same urban scheme and urban parameters,

226 suggest that the WRF model performs well at simulating the regional-urban rainfall (Dasari

227 et al. 2017; Dasari et al. 2019; Viswanadhapalli et al. 2017; Yesubabu et al. 2016).

\section{3. Effect of urbanization on the rainfall pattern}

229 The simulations of the extreme event that occurred on 25 November 2009 are first analyzed

230 in details to evaluate the land coverage effects on precipitation. The other nine cases of the

231 similar synoptic condition that produce heavy rainfall in Jeddah are then added to have a

232 statistical assessment of the rainfall modification from urbanization. As mentioned above,

233 the land surface cover in the URBAN simulation includes the city signatures of major areas

234 (Jeddah, Mecca, and Taif) in the convection-permitting domain through the use of the

235 Urban Canopy scheme (Fig. 2). Information regarding how precipitation changes and how

236 this can be explained from the standpoint of changes in meteorological conditions at the

237 surface and in the local atmosphere, is provided in the subsequent sub-sections.

238 a. Urbanization impacts on model-simulated precipitation

239 Observed and modeled precipitation for the time period 0000 UTC 25 November 2009, to

2400000 UTC 26 November 2009, along with the difference in simulated precipitation over

241 the Jeddah area, are shown in Fig. 3. The area of interest (Jeddah City) is circled.

242 Interestingly, the southwest-northeast direction and position of the maxima over Jeddah

243 (Fig. 3c) are well captured by the model in the URBAN experiment, which represents the

244 real-world scenario (Fig 3.a). The model reasonably represents an MCS within its domains.

245 The WRF model simulations tend to overestimate precipitation in the upper and lower third 
246 of the domain in comparison to the radar observations. However, the model result is in very

247 good agreement with the actual observations (on the order of $100 \mathrm{~mm} \mathrm{day}^{-1}$ ) in the center

248 of the domain over Jeddah (Fig. 3). This rainfall pattern indicates a robust performance

249 from the model.

250 With that in mind, we focused our attention to the effect of urbanization on

251 precipitation, which is the primary objective of this study. Figure $3 \mathrm{~d}$ shows that

252 precipitation consistently falls over the city in the URBAN simulation compared to the

253 DESERT simulation. The area of the Jeddah City in the DESERT experiment exhibited a

254 wider range of rainfall amount, from about 50 to over $140 \mathrm{~mm} \mathrm{day}^{-1}$ (Fig. 3b). In contrast,

255 in the URBAN experiment, the lowest range was $70 \mathrm{~mm} \mathrm{day}^{-1}$ (Fig. 3a). The URBAN

256 simulation also revealed a larger area of maxima (over $140 \mathrm{~mm} \mathrm{day}^{-1}$ ) in the south of the

257 city. Using urban land cover and the UCM in the URBAN simulation increased the average

258 daily precipitation over Jeddah by over $30 \%$ (93.45 $\mathrm{mm}^{-1 a y}{ }^{-1}$ compared to $71.83 \mathrm{~mm}^{-}$day $^{-}$

$259{ }^{1}$ in the DESERT simulation). Notably, the differences in rainfall patterns from the two

260 experiments were widespread along the coast. Immediately to the north and south of Jeddah

261 City, outside the urban core, decreases in the precipitation area are observed in the URBAN

262 simulation. In contrast, a significant increase of URBAN rainfall was recorded around

263 Jeddah, where the land tiles were changed and where the peak rainfall occurred.

264 Consequently, we were interested in investigating two questions: what is the physical

265 explanation of the differences in the rainfall pattern over Jeddah? And why the urban effect

266 is significantly noticeable?

267 b. Urban heat island and its association to the progress of thunderstorms 
268 Hourly analysis of the progress of thunderstorms during this extreme weather event may

269 provide more physical insights about the storm evolution and into how sensitive that

270 process was to the presence of the city of Jeddah. The simulated rainstorm moved from the

271 northwest to the southeast, passing over Jeddah at about 0700-0800 UTC (Fig. 4a-f). The

272 early morning storm seemed to propagate faster in the DESERT experiment, resulting in a

273 negative difference area located next to a positive area paralleling the direction of the storm

274 movement (Fig. 4g-i). These differences were mostly revealed after the storm approached

275 the city vicinity (after $0700 \mathrm{UTC}$ ) with rainfall intensity over $100 \mathrm{~mm} \mathrm{hour}^{-1}$. Jeddah City

276 was exposed to heavier and more prolonged rainfall rates in the URBAN experiment. This

277 implies a blocking or enhancing feature that reduced the propagation speed of the storm in

278 the URBAN experiment. The change in land use was next investigated to assess any direct

279 connection with the differences in precipitation.

280 Modeled surface heat fluxes (sensible and latent) along with precipitation and

281 boundary layer height diurnal cycles are presented in Fig. 5. During the nighttime and early

282 morning hours before the arrival of the storm (from 0000 UTC to 0600 UTC), the sensible

283 and latent heat flux of the two simulations were minimal and practically not distinguishable.

284 The boundary layer, however, was deeper before any convective activity takes place in the

285 URBAN experiment. The boundary layer height started to increase from 0200 UTC (200-

$286300 \mathrm{~m})$ to $0500 \mathrm{UTC}(900-1000 \mathrm{~m})$, with the increase occurring earlier in the URBAN

287 than in the DESERT experiment (double at 0300 UTC). The deeper PBL therefore locally

288 intensified the atmospheric instability over the urban area, in comparison to the

289 surrounding desert (Stull 1988). This is an important indication of the impact of

290 urbanization. 
Heat storage relative to desert soils is shown in Fig. 6. Urban surfaces in all the

292 cities of the region consistently exhibited higher surface temperature from 0000 to 0400

293 UTC, relative to the desert. The existence of a nocturnal urban heat island could be the

294 reason to modify the movement of the thunderstorm cells around Jeddah in the simulations.

295 Higher heat storage in the URBAN simulation provided instability in the environment for

296 a couple of hours before the storm. That condition favored rapid cyclogenesis, as revealed 297 next in Fig. 7.

298 The influence of urbanization on the intensification of heavy rainfall over Jeddah

299 due to land-use/land cover and the UCM was about 30\% of the total averaged daily

300 precipitation. This was mainly due to strong convergence at the lower levels, with deep

301 convection caused by strong vertical motion leading the development of mesoscale upper-

302 air cyclonic circulation. The dynamical mechanism behind the extreme event was

303 investigated using the vorticity tendency equation. The analysis of the vorticity equation

304 allows us to evaluate the contributions of the terms describing the different dynamical and

305 physical processes. The vorticity equation in an isobaric coordinate system can be written

306 as

$307 \frac{\partial \zeta}{\partial t}=-\left(u \frac{\partial}{\partial x}+v \frac{\partial}{\partial y}\right)(\zeta+f)-\omega \frac{\partial \zeta}{\partial P}-(\zeta+f)\left(\frac{\partial u}{\partial x}+v \frac{\partial v}{\partial y}\right)+\left(\frac{\partial u}{\partial P} \frac{\partial \omega}{\partial y}-\frac{\partial v}{\partial P} \frac{\partial \omega}{\partial x}\right)+\left(\frac{\partial F_{y}}{\partial x}-\frac{\partial F_{x}}{\partial y}\right)$.

308 The horizontal advection of absolute vorticity is represented by the first term on the right-

309 hand side. The second term denotes the vertical advection of relative vorticity. The third

310 term (called the stretching term) indicates the divergence acting on absolute vorticity. The

311 fourth term denotes the tilting of vertically sheared flow. And the last term represents

312 gradients in the force of friction. The different terms of the vorticity tendency equation

313 over Jeddah for both URBAN and DESERT experiments were computed hourly based on 
314 the model simulations. The time-height sections between 0200 UTC and 1300 UTC of 25

315 November 2009, of the vorticity terms, are presented in Fig. 7. The vorticity tendency is

316 relatively small $\left(1 \times 10^{-8} \mathrm{~s}^{-2}\right)$ until 0600 UTC of 25 November 2009 in both experiments

317 (Fig. 7a-b). A significant increase (more than $50 \times 10^{-8} \mathrm{~s}^{-2}$ ) of the vorticity tendency was

318 noticeable until 0800 UTC. In URBAN, the vorticity tendency is concentrated between the

319 surface and $100 \mathrm{hPa}$ (Fig. 7a) and in DESERT it extends to $600 \mathrm{hPa}$ (Fig. 7b). In URBAN,

320 the cyclonic vorticity exhibited a tower shape that persisted for about three hours from

3210600 UTC to 0900 UTC, whereas in DESERT, the experimental cyclonic vorticity initially

322 persisted for about one hour (up to $0700 \mathrm{UTC}$ ) and extended to around $600 \mathrm{hPa}$. It then

323 became negative, indicating anti-cyclonic vorticity (until 0800 UTC) before it turns

324 cyclonic again for about one hour (0900 UTC). This suggests that the URBAN experiment

325 experienced a substantial increase of cyclonic vorticity that persisted longer than in the

326 DESERT experiment, which means that the inclusion of the URBAN conditions enhanced

327 the strength and duration of the storm.

328 The analysis of the different terms of the vorticity tendency equation suggests that

329 the horizontal (Fig. 7c-d) and vertical (Fig. 7e-f) advection, stretching (Fig. g-h) terms are

330 the main factors contributing to the vorticity dynamics. The horizontal advection in

331 URBAN (Fig. 7c) shows that it positively contributed to the increase of vorticity in the

332 lower layers (below $600 \mathrm{hPa}$ ) for about four hours by transporting the moisture from

333 regions of the neighboring Red Sea. In DESERT (Fig. 7d), however, the horizontal

334 advection exhibited a shape of a narrow tower extending up to $300 \mathrm{hPa}$ for about 1-2 hours.

335 The vertical advection and stretching terms in URBAN (Fig. 7e, g) exhibits higher

336 magnitudes than those in DESERT from 800 to $400 \mathrm{hPa}$. This establishes that the lifting of 
337 moisture to the upper levels by strong vertical motions enables deeper convection in

338 URBAN. The higher magnitudes of the stretching term in URBAN also indicates a more

339 significant increase in the low-level convergence than in DESERT. Analysis of the last

340 term in Fig. 7i, j demonstrates that the negative influence of the tilting term on the vorticity

341 tendency in the upper atmosphere, which led to the dissipation of the system, is observed

342 in both experiments. There is, however, a positive contribution to the vorticity in the lower

343 layers in URBAN (Fig. 7i) that is not realized in the DESERT experiment (Fig. 7j).

344 In summary, the rise of convection activities in the URBAN experiment was due to

345 higher and longer positive vorticity advection, stronger upward motion, greater surface

346 convergence, and increased amount of low-level moisture convergence from the Red Sea

347 region and low vertical wind shear. This suggests that urbanization was an important factor

348 in the storm development and associated rainfall intensify over the city of Jeddah.

349 We also conducted a moisture analysis to assess how storms are affected in this

350 coastal city. Fig. 8 represents the moisture available in the region via the total column water

351 (TCW) in millimeters for both experiments $(a, b)$ and their differences (c, d) averaged from

$3520000 \mathrm{UTC}$ to $0800 \mathrm{UTC}$. The figure was plotted within a zoomed-in perspective to show

353 the gradient of moisture from sea to land. An east-west gradient is observed overall in the

354 domain with drier area inland and moister area near the coast. East of $40.2^{\circ} \mathrm{E}$, the TCW is

355 quite dry with only 10 to $20 \mathrm{~mm}$. TWC in the Jeddah area ranged from more than $40 \mathrm{~mm}$

356 to $55 \mathrm{~mm}$ for both experiments (Fig. $8 \mathrm{a}-\mathrm{b}$ ). The differences, however, suggest a significant

357 increase in moisture in the URBAN case, specifically around Jeddah. Changes in land-use

358 primarily increase the TCW by about $2.06 \mathrm{~mm}$, or about $4.25 \%$ in URBAN. With natural 
359 land surfaces instead of the city, the DESERT experiment simulated 4.25\% less moisture 360 (Fig. 8 c-d).

361 Vertically integrated horizontal water vapor fluxes (IVF) $\left[\mathrm{kg} \mathrm{m}^{-1} \mathrm{~s}^{-1}\right]\left(\frac{1}{g} \int_{p_{s}}^{p_{t}} q \boldsymbol{V} d p\right)$

362 or moisture fluxes are analyzed in Fig. 9. A flow of moisture is initiated from the Red Sea

363 predominantly from the south-southwest (Fig. 9 a-b) perpendicular to the general direction

364 of the storm, which is from the north-northwest. Additional moisture from the Red Sea to

365 the Jeddah area accumulated hours before the arrival of the storm. This added energy was

366 vital for the MCS development and propagation and provided a cold pool development

367 mechanism for the MCS. An enhancement of the flux is observed in the URBAN

368 experiment (Fig. 9c). The stronger moisture flux simulated by URBAN paved the way for

369 stronger storm development, and hence increasing the precipitation intensity. It is to be

370 noted that land-use affects both the dynamics (Fig. 7) and the thermodynamics (Fig. 8-9)

371 of the MCS. The extreme Jeddah precipitation event occurred because of its unique

372 location near the Red Sea and because of the prevailing synoptic conditions of the day.

373 Urbanization enhanced the development of the storm by providing more favorable

374 thermodynamics and dynamics conditions.

375 c. General feature of urban precipitation enhancement

376 To further support the results of urbanization impact on the Jeddah city rainfall, we

377 extended our simulations for a total of ten case studies of extreme precipitation over Jeddah.

378 The considered ten events are selected due to their similar synoptic/mesoscale features

379 following a dominant mode that produce heavy rainfall over the city of Jeddah. These

380 events are associated with strong tropical-extratropical interactions and the presentation of

381 the RST. Thunderstorms are initiated by the upper-level trough intrusion into low latitudes. 
382 A combination of stationary Arabian anticyclone, low-level convergence, and deep moist

383 convection produce extreme rainfall in these cases (ALKhalaf A. and Abdel Basset H.

384 2013; Dasari et al. 2018; Haggag and El-Badry 2013; Kumar et al. 2016). Simulated rainfall

385 from the two experiments and their differences for all ten heavy rainfall events are

386 displayed in Figure 10. All cases exhibit enhancement of precipitation over the city of

387 Jeddah. Composite mean of the ten cases also outlines the same conclusion (Fig. 11). Both

388 URBAN and DESERT show similar patterns but the peaks of rainfall occur at different

389 locations (Fig. $11 \mathrm{a}, \mathrm{b}$ ). Mean rainfalls in the Jeddah area (over circled region) are $46.2 \mathrm{~mm}$

390 and $36.8 \mathrm{~mm}$ for URBAN and DESRT experiments, respectively.

391 Rainfall changes from urbanization is about $26 \%$ on average over the 10 heavy

392 rainfall events (Table 1). All these convective events occurred at night time in the winter.

393 Storm directions are generally from the Southwest to Northwest. Nocturnal urban heat

394 island is revealed by surface temperature with a mean increase of $0.36 \mathrm{~K}$. Sensible and

395 latent heat fluxes differences are minimal before sunset. The boundary layer, however, is

396 deeper in the URBAN experiment with a mean increase of $76.7 \mathrm{~m}$, about $24 \%$. Total

397 column water is $1.3 \mathrm{~mm}(3 \%)$ higher in the URBAN experiment (Table 1). These indicators

398 suggest that URBAN exhibits more favorable thermodynamic and dynamic conditions to

399 strengthen convective activities. The urban surface therefore acts as a redistributor, which

400 enhances rainfall in the city and reduces it around the city.

401 Because of the lack of an observation network in the Jeddah region, we analyze the

402 spatial distribution of heavy rainfall events and associated trends over Jeddah using 403 different gridded rainfall datasets: the climate prediction centre MORPHing (CMORPH)

404 (Joyce et al. 2004) and the tropical rainfall measuring mission (TRMM) (Huffman et al. 
2007). Both datasets available at a resolution of $0.25^{\circ}$ indicate a significant increase in

406 heavy rainfall events intensity in recent decades over Jeddah (Fig. 12). Analyses from

407 modeling and observational data are therefore in agreement regarding the increase in

408 intensity of heavy rainfall over Jeddah, due to urbanization as suggested by our modeling

409 study. Observations from the sole station that have long term daily precipitation records in

410 Jeddah from Ministry of Water and Electricity (MOWE) also imply a significant rainfall

411 trend in the urban core (Fig. 13). The precipitation trend is increasing overall with a slope

412 of $+0.51\left[\mathrm{~mm}\right.$ year $\left.{ }^{-1}\right]$ based on linear regression. This is in agreement with the increasing

413 trends from TRMM and CMORPH (Fig. 12) for the city of Jeddah.

414 Different from other desert cities, e.g. Phoenix, where North American monsoon

415 precipitation in the summer plays an important role (Georgescu et al. 2008, 2009), the

416 majority of Jeddah heavy precipitation is produced by MCSs in the winter propagating to

417 the city at night to the early morning. The physical process that enhances precipitation in

418 the city area and reduce rainfall outside of the city is a "heat island" effect that leads to a

419 deeper boundary layer, stronger baroclinicity, and a more unstable atmosphere inside the

420 city.

\section{4. Discussion and Conclusions}

422 Numerical simulations and flux tower observation studies have suggested that the

423 daytime cooling of the urban area (oasis-effect) relative to the surrounding desert is due to

424 increased heat storage in the urban fabric, rather than changes in latent heat fluxes (Chow

425 et al. 2014; Georgescu et al. 2011; Grossman-Clarke et al. 2010). The very substantial heat

426 storage fluxes in the urban core are caused by a reduced albedo and increase in the surface

427 area from complex urban structures. During nighttime this stored heat is released and 
428 therefore cities in arid environments, including Jeddah, are characterized by relatively large

429 urban heat island effects and increased planetary boundary layer height.

430 Ten heavy rainfall events associated with similar synoptic/mesoscale features

431 related to a cold midlatitude upper-level trough, a stationary Arabian anticyclone, low-level

432 convergence, and deep moist convection are analyzed to study the impact of urbanization

433 on the Jeddah city rainfall. Simulations from the URBAN and DESERT experiments for

434 all ten heavy rainfall events suggested an enhancement in precipitation of about $26 \%$, on

435 average, inside the city area in the URBAN experiment. Observations from different

436 gridded rainfall datasets also indicated an increase in the intensity of heavy rainfall events

437 over Jeddah in recent years. One of the extreme weather events from the 10-event set that

438 occurred on 25 November 2009 is analyzed in details to assess how urbanization affects

439 thunderstorms.

440 An urban canopy model was used within WRF to explicitly account for urban

441 surfaces. Two 30-hour convection-permitting simulations were performed per each event:

442 an URBAN experiment used the UCM, and a DESERT experiment removed the city and

443 replaced it with its natural desert land surface cover. Changes in the simulations related to

444 precipitation pattern, thunderstorm progress, heat fluxes, depth of the boundary layer,

445 cyclogenesis dynamics, and moisture fluxes were analyzed. Our primary conclusion from

446 the model sensitivity experiments is that the city of Jeddah urban area exhibits a nocturnal

447 "heat island" effect that leads to a deeper boundary layer, stronger baroclinicity, and a more

448 unstable atmosphere. These factors have favored convective activities, initiating the

449 development of thunderstorms, and increasing urban rainfall. Relatively to the direction of

450 the upper-level flow, rainfall decreases immediately downwind of the city to the southeast. 
451 The enhancement of rainfall by urbanization is concurrent with an Active Red Sea Trough

452 weather phenomenon that produce heavy rainfall in the winter.

453 An unsettled question was not addressed in the present study: which specific

454 components of the UCM physics is most critical for explaining the model simulated

455 differences in precipitation? Additional model experiments to investigate the sensitivity of

456 the model to the individual UCM physical components are therefore needed to further

457 assess this urbanization effect in the coastal city of Jeddah.

459 Acknowledgements

460 This work was funded by King Abdullah University of Science and Technology

461 (KAUST) under the Virtual Red Sea Initiative Grant \# REP/1/3268-01-01. The research

462 made use of the Supercomputing Core Laboratory resources at KAUST. Parts of the

463 material in Sections 1 and 2 first appeared in Appendix B of Chapter 2 from (Luong 2015)

464 and are repeated here for the readers' information.

465

466 References

467 ALKhalaf A., and Abdel Basset H., 2013: Diagnostic Study of a Severe Thunderstorm over $468 \quad$ Jeddah. Atmospheric and Climate Sciences, 3, 150-164.

469 Alqurashi, A. F., and L. Kumar, 2016: Spatiotemporal patterns of urban change and 470 associated environmental impacts in five Saudi Arabian cities: A case study using 471 remote sensing data. Habitat Int, 58, 75-88. 
472 Argueso, D., A. Di Luca, and J. P. Evans, 2016: Precipitation over urban areas in the 473 western Maritime Continent using a convection-permitting model. Climate 474 Dynamics, 47, 1143-1159.

475 Bornstein, R., and M. LeRoy, 1990: Urban barrier effects on convective and frontal 476 thunderstorms. Preprint volume, Fourth AMS Conference on Mesoscale Processes, 477 Boulder, CO, 25-29 June.

478 Bornstein, R., and Q. L. Lin, 2000: Urban heat islands and summertime convective 479 thunderstorms in Atlanta: three case studies. Atmos Environ, 34, 507-516.

480 Burian, S. J., and J. M. Shepherd, 2005: Effect of urbanization on the diurnal rainfall pattern 481 in Houston. Hydrol Process, 19, 1089-1103.

482 Changnon, S. A., 2001: Assessment of historical thunderstorm data for urban effects: The 483 Chicago case. Climatic Change, 49, 161-169.

484 Chen, F., and Coauthors, 2011: The integrated WRF/urban modelling system: development, 485 evaluation, and applications to urban environmental problems. International

487 Chow, W. T. L., T. J. Volo, E. R. Vivoni, G. D. Jenerette, and B. L. Ruddell, 2014: Seasonal 488 Journal of Climatology, 31, 273-288.

490 Corfidi, S. F., 2003: Cold pools and MCS propagation: Forecasting the motion of 491 downwind-developing MCSs. Weather and Forecasting, 18, 997-1017.

492 Cotton, W. R., and R. A. Pielke, 2007: Human impacts on climate. Cambridge University 493 Press, $330 \mathrm{pp}$. 
494 Dasari, H. P., R. Attada, O. Knio, and I. Hoteit, 2017: Analysis of a severe weather event over Mecca, Kingdom of Saudi Arabia, using observations and high-resolution modelling. Meteorol Appl, 24, 612-627.

497 Dasari, H. P., S. Langodan, Y. Viswanadhapalli, B. R. Vadlamudi, V. P. Papadopoulos, and I. Hoteit, 2018: ENSO influence on the interannual variability of the Red Sea convergence zone and associated rainfall. International Journal of Climatology, 38,

de Vries, A. J., E. Tyrlis, D. Edry, S. O. Krichak, B. Steil, and J. Lelieveld, 2013: Extreme

Dasari, H. P., and Coauthors, 2019: High-resolution assessment of solar energy resources $761-775$.

de Vries, A. J., and Coauthors, 2016: Dynamics of tropical-extratropical interactions and precipitation events in the Middle East: Dynamics of the Active Red Sea Trough. Journal of Geophysical Research-Atmospheres, 118, 7087-7108. extreme precipitation events in Saudi Arabia in autumn, winter and spring. Q J Roy Meteor Soc, 142, 1862-1880.

Dee, D. P., and Coauthors, 2011: The ERA-Interim reanalysis: configuration and performance of the data assimilation system. Q J Roy Meteor Soc, 137, 553-597.

Deng, L. P., M. F. McCabe, G. Stenchikov, J. P. Evans, and P. A. Kucera, 2015: Simulation of Flash-Flood-Producing Storm Events in Saudi Arabia Using the Weather Research and Forecasting Model. Journal of Hydrometeorology, 16, 615-630.

515 Central Arizona, U.S.A. The Professional Geographer, 55, 343-355. 
516 Georgescu, M., G. Miguez-Macho, L. T. Steyaert, and C. P. Weaver, 2008: Sensitivity of 517 summer climate to anthropogenic land-cover change over the Greater Phoenix, AZ, 518 region. J Arid Environ, 72, 1358-1373.

$519-$ 2009: Climatic effects of 30 years of landscape change over the Greater Phoenix, 520 Arizona, region: 2. Dynamical and thermodynamical response. Journal of $521 \quad$ Geophysical Research-Atmospheres, 114.

522 Georgescu, M., M. Moustaoui, A. Mahalov, and J. Dudhia, 2011: An alternative 523 $524 \quad$ Research-Atmospheres, 116.

525 Gero, A. F., and A. J. Pitman, 2006: The impact of land cover change on a simulated storm 526 event in the Sydney basin. J Appl Meteorol Clim, 45, 283-300.

527 Grossman-Clarke, S., J. A. Zehnder, T. Loridan, and C. S. B. Grimmond, 2010: 528 Contribution of Land Use Changes to Near-Surface Air Temperatures during 529 Recent Summer Extreme Heat Events in the Phoenix Metropolitan Area. J Appl $530 \quad$ Meteorol Clim, 49, 1649-1664.

531 Haggag, M., and H. El-Badry, 2013: Mesoscale Numerical Study of Quasi-Stationary 532 Convective System over Jeddah in November 2009. Atmospheric and Climate $533 \quad$ Sciences, Vol.03No.01, 14.

534 Hand, L. M., and J. M. Shepherd, 2009: An Investigation of Warm-Season Spatial Rainfall 535 Variability in Oklahoma City: Possible Linkages to Urbanization and Prevailing $536 \quad$ Wind. J Appl Meteorol Clim, 48, 251-269. 
537 Huffman, G. J., and Coauthors, 2007: The TRMM multisatellite precipitation analysis

538 (TMPA): Quasi-global, multiyear, combined-sensor precipitation estimates at fine 539 scales. Journal of Hydrometeorology, 8, 38-55.

540 Iacono, M. J., J. S. Delamere, E. J. Mlawer, M. W. Shephard, S. A. Clough, and W. D.

541 Collins, 2008: Radiative forcing by long-lived greenhouse gases: Calculations with

542 the AER radiative transfer models. Journal of Geophysical Research-Atmospheres,

$543 \quad 113$.

544 Janjic, Z., 2002: Nonsingular Implementation of the Mellor-Yamada Level 2.5 Scheme in 545 the NCEP Meso model.

546 Janjic, Z. I., 1994: The Step-Mountain Eta Coordinate Model - Further Developments of 547 the Convection, Viscous Sublayer, and Turbulence Closure Schemes. Monthly $548 \quad$ Weather Review, 122, 927-945.

549 Joyce, R. J., J. E. Janowiak, P. A. Arkin, and P. P. Xie, 2004: CMORPH: A method that 550 produces global precipitation estimates from passive microwave and infrared data 551 at high spatial and temporal resolution. Journal of Hydrometeorology, 5, 487-503.

552 Kendon, E. J., and Coauthors, 2017: Do Convection-Permitting Regional Climate Models 553 Improve Projections of Future Precipitation Change? Bulletin of the American $554 \quad$ Meteorological Society, 98, 79-+.

555 Kumar, K. N., T. B. M. J. Ouarda, S. Sandeep, and R. S. Ajayamohan, 2016: Wintertime 556 precipitation variability over the Arabian Peninsula and its relationship with ENSO 557 in the CAM4 simulations. Climate Dynamics, 47, 2443-2454. 
558 Kusaka, H., and F. Kimura, 2004: Coupling a single-layer urban canopy model with a 559 simple atmospheric model: Impact on urban heat island simulation for an idealized case. J Meteorol Soc Jpn, 82, 67-80.

561 Kusaka, H., H. Kondo, Y. Kikegawa, and F. Kimura, 2001: A simple single-layer urban 562 canopy model for atmospheric models: Comparison with multi-layer and slab models. Bound-Lay Meteorol, 101, 329-358.

564 Kusaka, H., A. Nishi, M. Mizunari, and H. Yokoyama, 2019: Urban impacts on the spatiotemporal pattern of short-duration convective precipitation in a coastal city adjacent to a mountain range. $Q J$ Roy Meteor Soc, 145, 2237-2254.

567 Kusaka, H., K. Nawata, A. Suzuki-Parker, Y. Takane, and N. Furuhashi, 2014: Mechanism 568 of Precipitation Increase with Urbanization in Tokyo as Revealed by Ensemble 569 Climate Simulations. J Appl Meteorol Clim, 53, 824-839.

570 Lahmers, T. M., C. L. Castro, D. K. Adams, Y. L. Serra, J. J. Brost, and T. Luong, 2016 : 571 Long-Term Changes in the Climatology of Transient Inverted Troughs over the North American Monsoon Region and Their Effects on Precipitation. Journal of

574 Luong, T. M., 2015: Severe weather during the North American monsoon and its response 575 to rapid urbanization and a changing global climate within the context of high 576 resolution regional atmospheric modeling. Ph.D. Dissertation, University of $577 \quad$ Arizona, $180 \mathrm{pp}$.

578 Luong, T. M., C. L. Castro, T. M. Nguyen, W. W. Cassell, and H. I. Chang, 2018: 579 Improvement in the Modeled Representation of North American Monsoon 
Precipitation Using a Modified Kain-Fritsch Convective Parameterization Scheme. Atmosphere-Basel, 9.

582 Luong, T. M., C. L. Castro, H. I. Chang, T. Lahmers, D. K. Adams, and C. A. Ochoa-Moya, 583 2017: The More Extreme Nature of North American Monsoon Precipitation in the $584 \quad$ Southwestern United States as Revealed by a Historical Climatology of Simulated 585 Severe Weather Events. J Appl Meteorol Clim, 56, 2509-2529.

586 Monin, A. S., and A. Obukhov, 1954: Basic laws of turbulent mixing in the surface layer of the atmosphere. Contrib. Geophys. Inst. Acad. Sci. USSR, 151, 163-187.

588 Morrison, H., and J. A. Milbrandt, 2015: Parameterization of Cloud Microphysics Based on the Prediction of Bulk Ice Particle Properties. Part I: Scheme Description and Idealized Tests. Journal of the Atmospheric Sciences, 72, 287-311.

591 Orville, R. E., and Coauthors, 2001: Enhancement of cloud-to-ground lightning over Houston, Texas. Geophys Res Lett, 28, 2597-2600.

593 Prein, A. F., and Coauthors, 2015: A review on regional convection-permitting climate 594 modeling: Demonstrations, prospects, and challenges. Rev Geophys, 53, 323-361.

595 Rozoff, C. M., W. R. Cotton, and J. O. Adegoke, 2003: Simulation of St. Louis, Missouri, 596 land use impacts on thunderstorms. J Appl Meteorol, 42, 716-738.

597 Shem, W., and M. Shepherd, 2009: On the impact of urbanization on summertime 598 599 thunderstorms in Atlanta: Two numerical model case studies. Atmos Res, 92, 172-

600 Shepherd, J. M., M. Carter, M. Manyin, D. Messen, and S. Burian, 2010: The Impact of 601 Urbanization on Current and Future Coastal Precipitation: A Case Study for 

304.

604 Skamarock, W. C., and Coauthors, 2008: A description of the Advanced Research WRF 605 version 3. NCAR Tech. Note NCAR/TN-475+STR, 1-113.

606 Stull, R. B., 1988: An Introduction to Boundary Layer Meteorology. Atmospheric Sciences 607 Library, 1383-8601 13, Springer Netherlands, 1 online resource (XIII, 670 pages).

608 Tewari, M., and Coauthors, 2004: Implementation and verification of the unified NOAH 609 land surface model in the WRF model. 20th conference on weather analysis and 610 forecasting/l6th conference on numerical weather prediction, Seattle, WA, UAS, $611 \quad$ January 14, 11-15.

612 Viswanadhapalli, Y., H. P. Dasari, S. Langodan, V. S. Challa, and I. Hoteit, 2017: Climatic 613 features of the Red Sea from a regional assimilative model. International Journal 614 of Climatology, 37, 2563-2581.

615 Yesubabu, V., C. V. Srinivas, S. Langodan, and I. Hoteit, 2016: Predicting extreme rainfall 616 events over Jeddah, Saudi Arabia: impact of data assimilation with conventional 617 and satellite observations. Q J Roy Meteor Soc, 142, 327-348.

618 


\section{$619 \quad$ Figures}

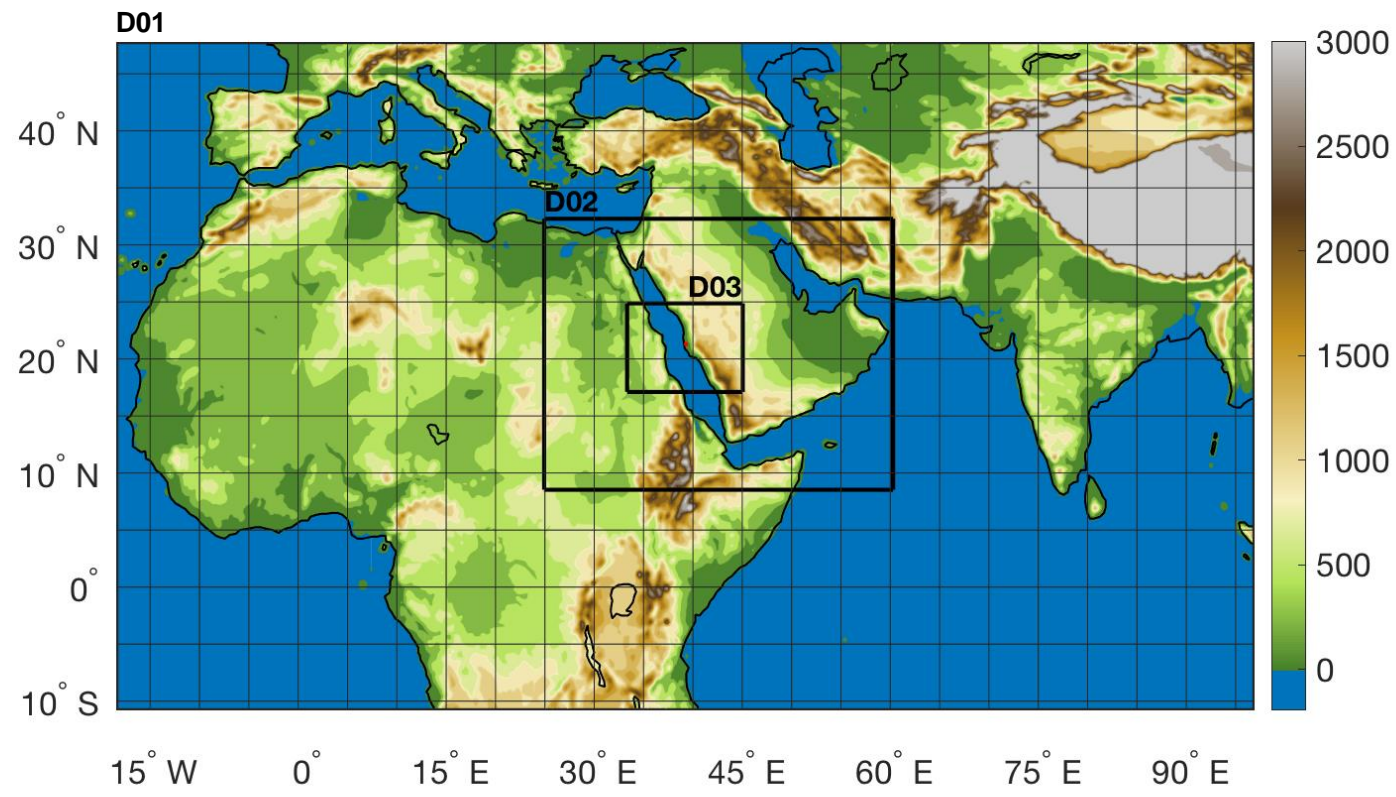

621 Figure 1: Positions of domains 2 and 3 with $4.5-\mathrm{km}$ and 1.5-km resolution, respectively, 622 inside the 22.5-km coarse resolution domain 1 map with terrain height shaded $(\mathrm{m})$. 

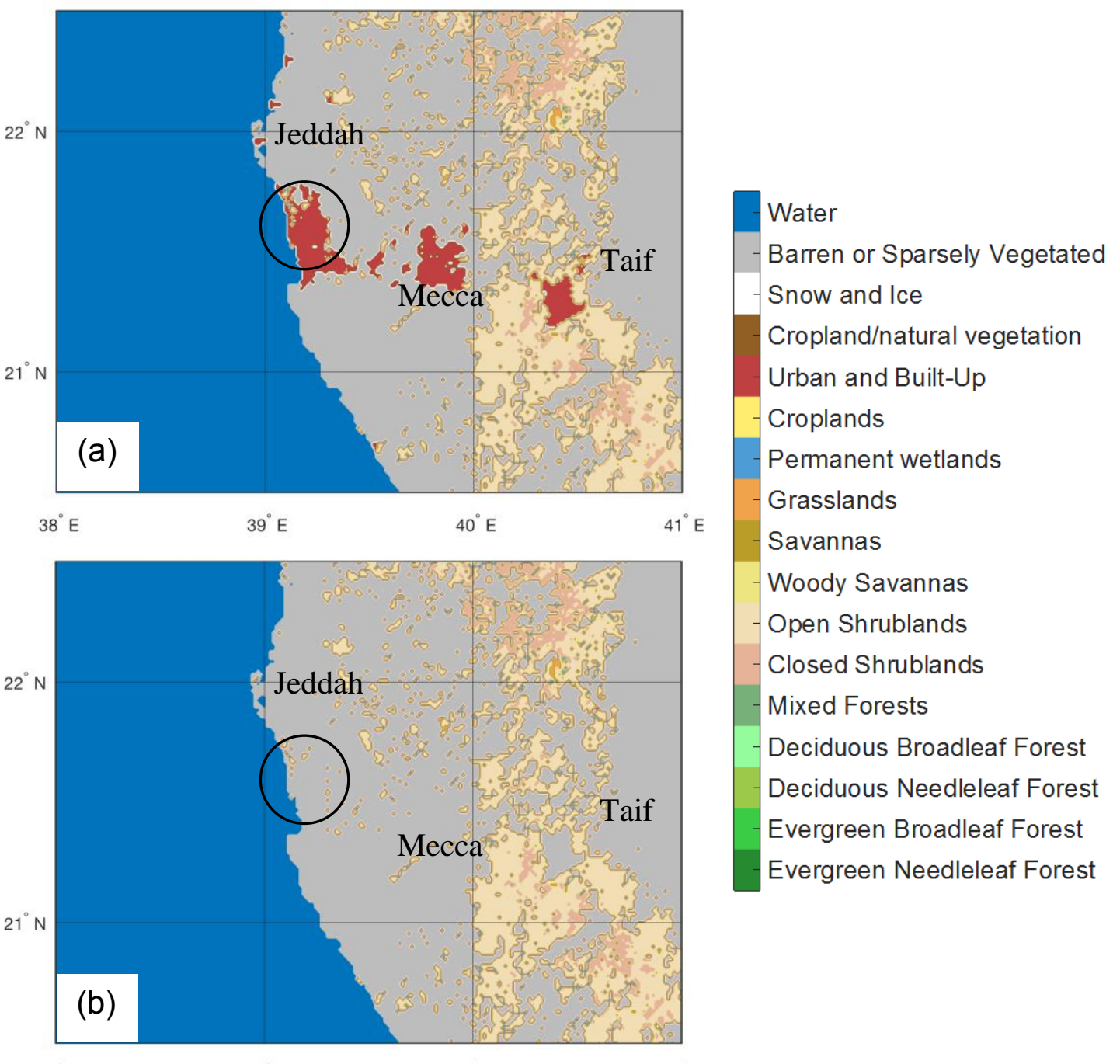

- Croplands

Permanent wetlands

Grasslands

Savannas

Woody Savannas

Open Shrublands

Closed Shrublands

Mixed Forests

Deciduous Broadleaf Forest

Deciduous Needleleaf Forest

Evergreen Broadleaf Forest

Evergreen Needleleaf Forest

$38^{\circ} \mathrm{E}$

$39^{\circ} \mathrm{E}$

$40^{\circ} \mathrm{E}$

$41^{\circ} \mathrm{E}$

624 Figure 2: Land-use index of (a) Modern (URBAN) and (b) Pre-settlement (DESERT) 625 experiments. Urban land-use tiles (category 13 - red) have been replaced by desert 626 (category 16 - gray) in the bottom panel. The Jeddah city area is circled. 

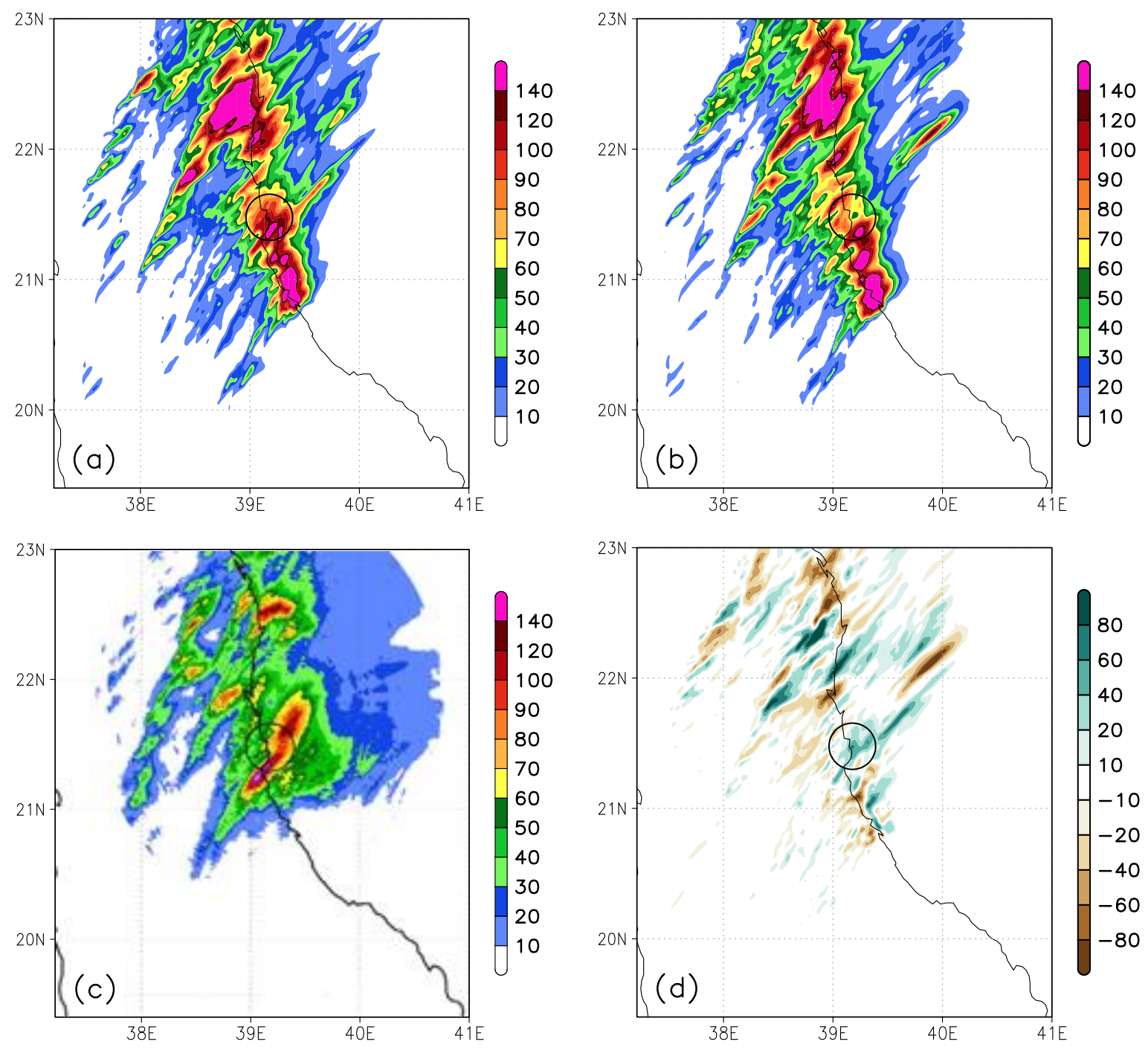

628 Figure 3: Simulated $24 \mathrm{~h}$ accumulated rainfall $\left[\mathrm{mm} \mathrm{day}^{-1}\right]$ on 25 November 2009 from the 629 two experiments (a) Urban and (b) Desert, (c) Observation from radar, and (d) Rainfall 630 differences (URBAN minus DESERT). The Jeddah city area is circled. 


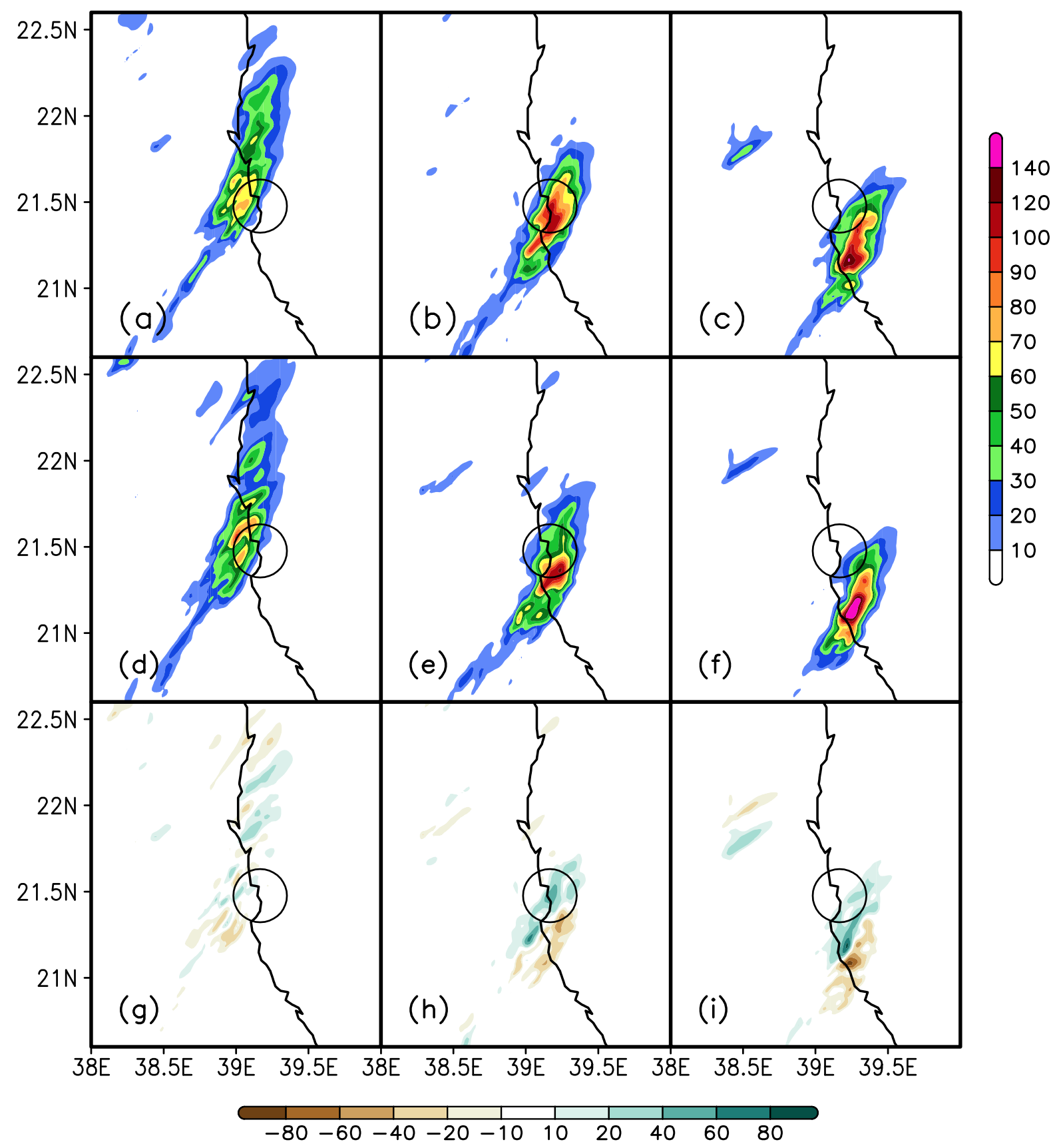

632 Figure 4: Evolution of the storm revealed by hourly precipitation [mm hour $\left.{ }^{-1}\right]$. URBAN, 633 DESERT, and their differences (URBAN minus DESERT) are plotted in (a-c) Upper, (d634 f) Middle, and (g-i) Bottom panels, respectively. Timeline from left to right: 0600-0700 635 UTC, 0700-0800 UTC, and 0800-0900 UTC on 25 November 2009. The Jeddah city area 636 is circled. 

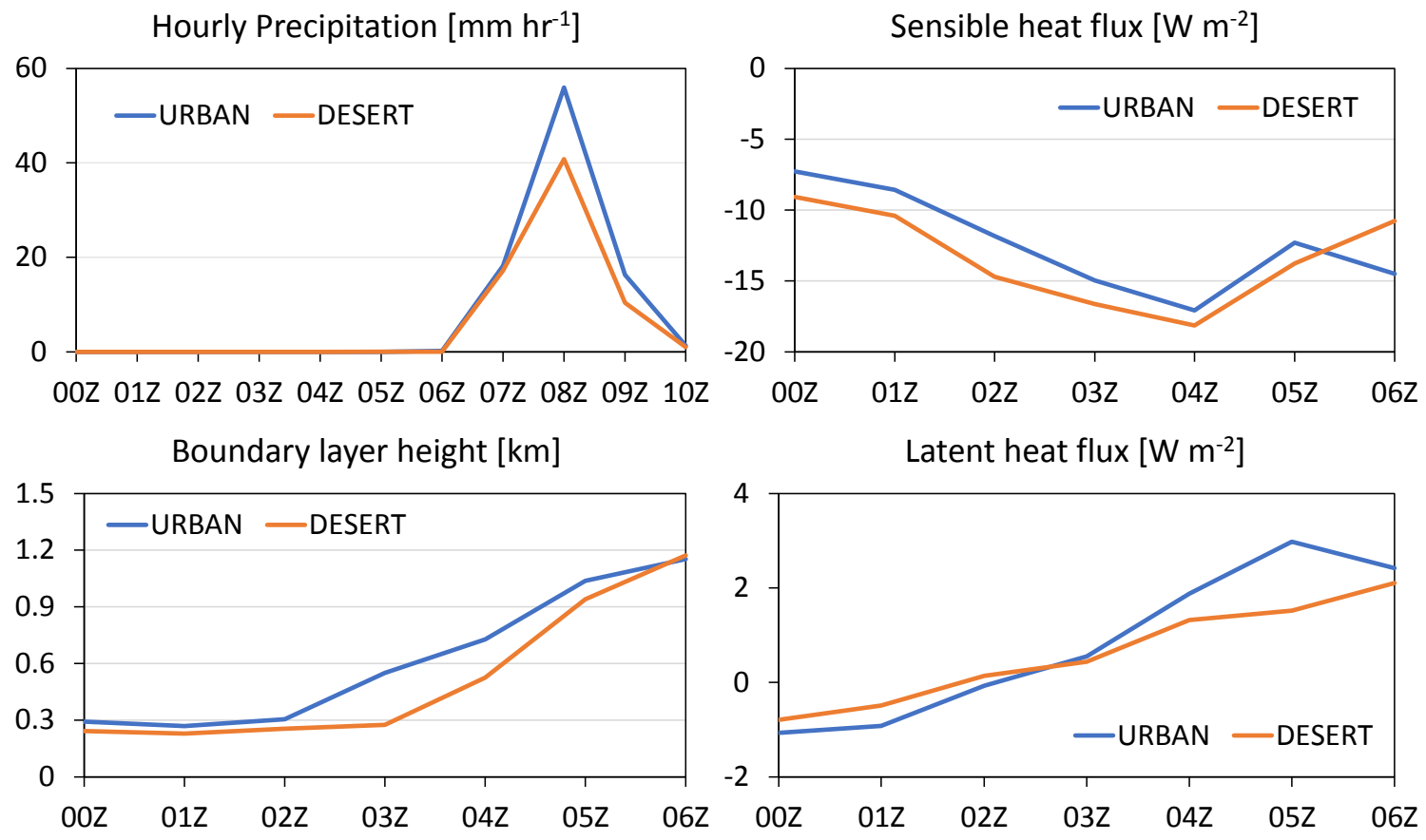

Figure 5: Hourly evolution of precipitation $\left[\mathrm{mm} \mathrm{hour}^{-1}\right]$, sensible and latent heat fluxes [W averages over Jeddah area. 


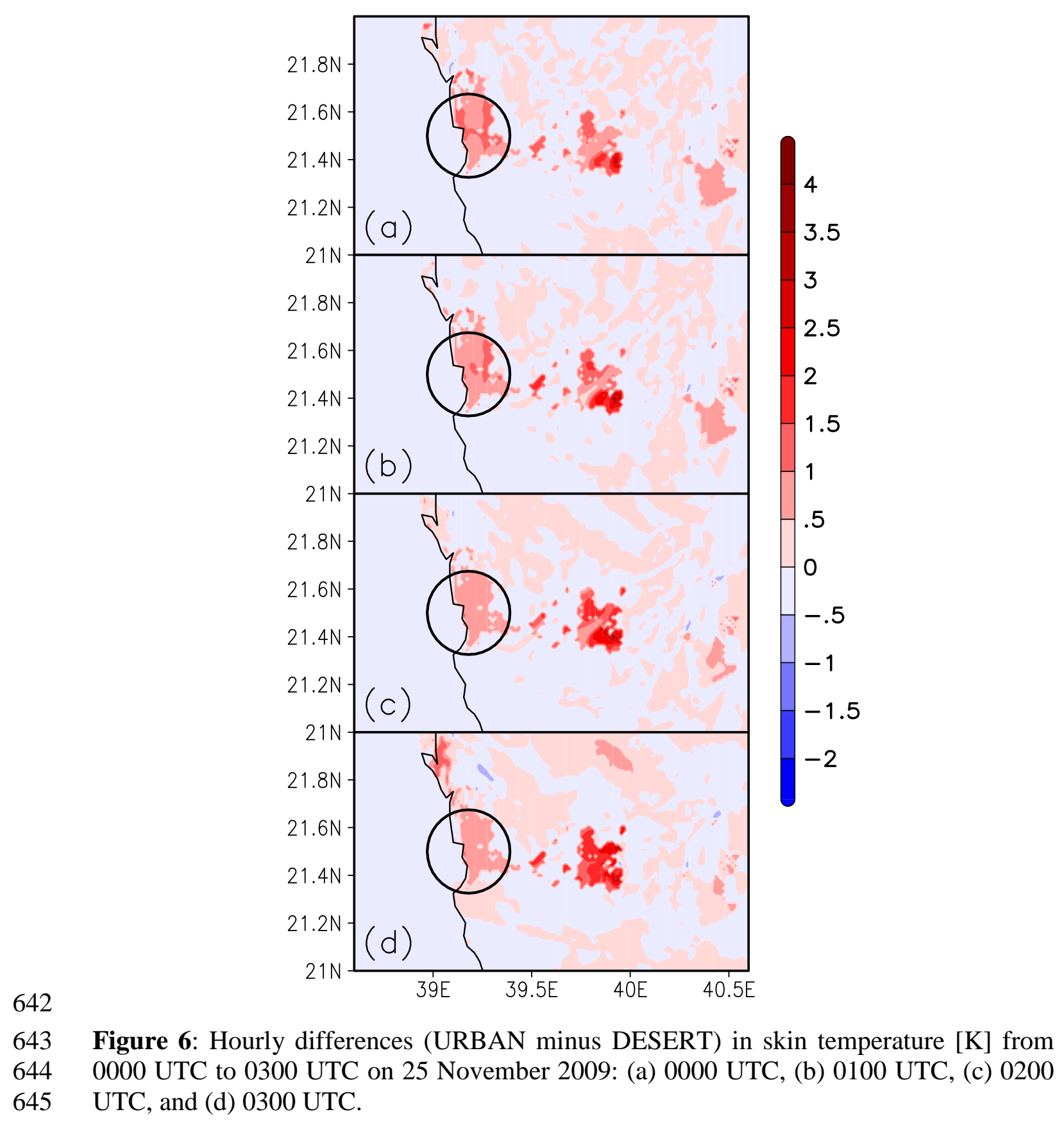

645 UTC, and (d) 0300 UTC. 


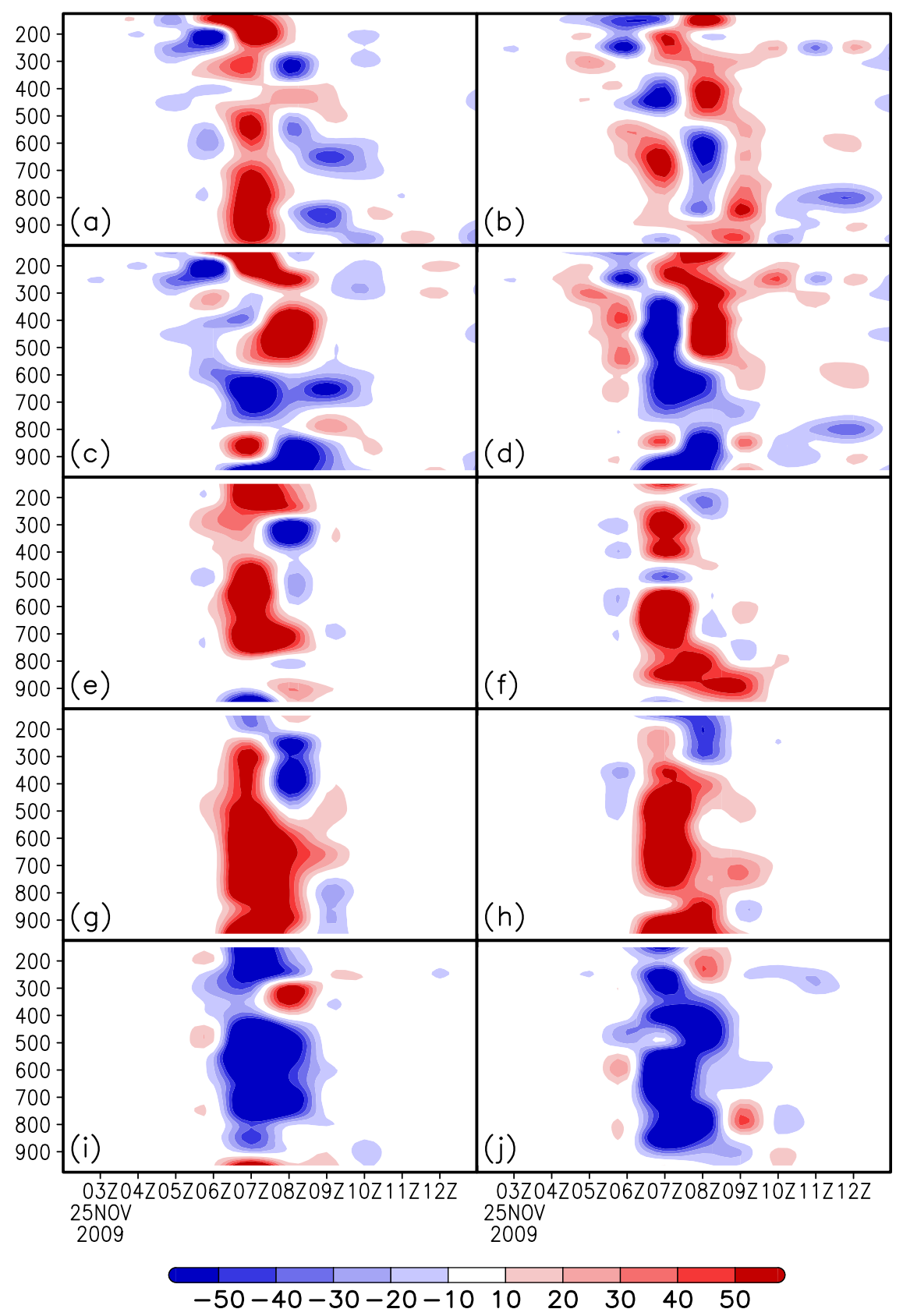

646

647 Figure 7: Vorticity tendency equation terms $\left[\times 10^{-8} \mathrm{~s}^{-2}\right]$ for the URBAN (left panels) and 648 DESERT (right panels) experiments: (a-b) Vorticity tendency, (c-d) Horizontal advection, 649 (e-f) Vertical advection, (g-h) Stretching, and (i-j) Tilting. 

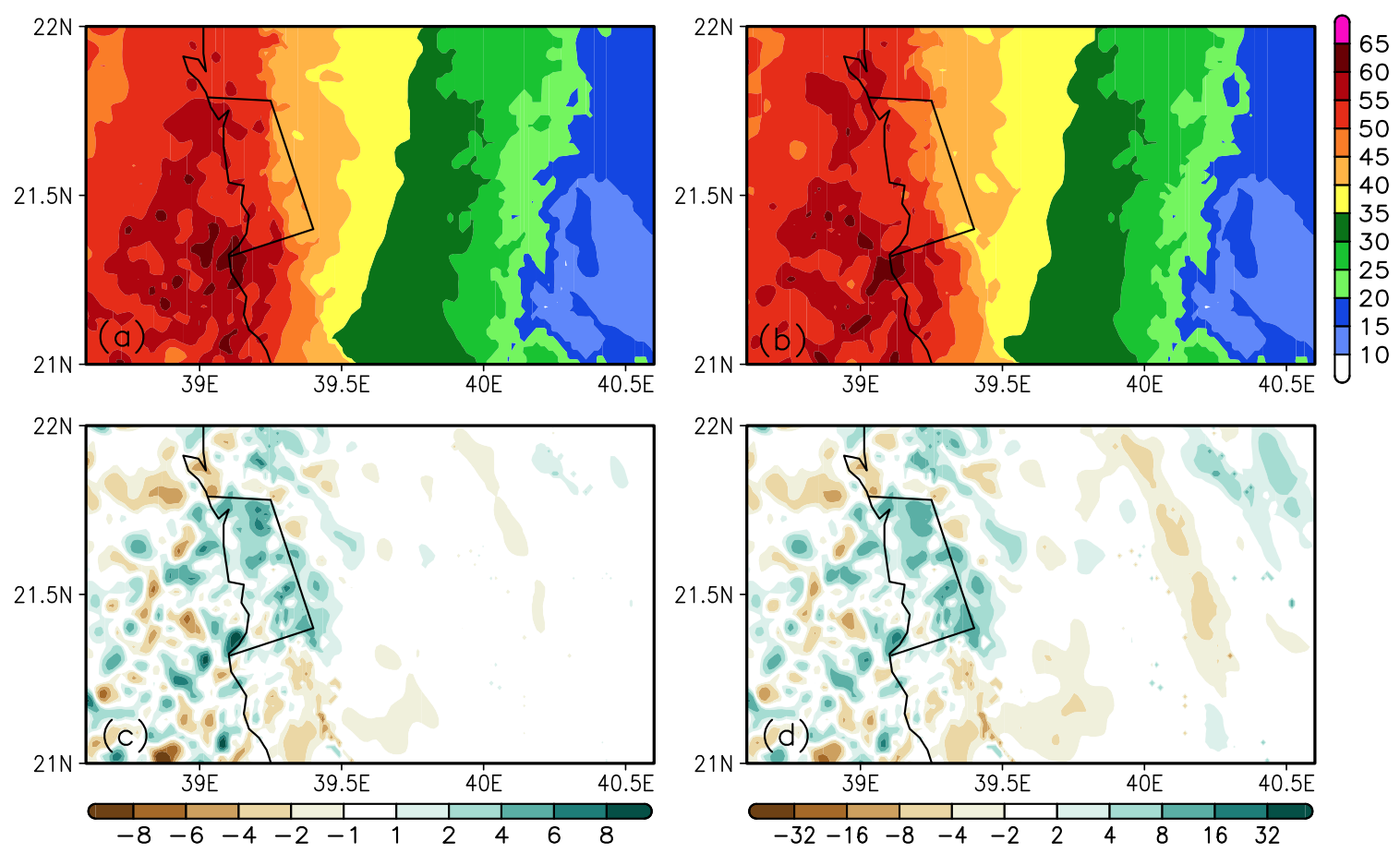

651 Figure 8: Total column water (TCW) [mm] averaged from 0000 UTC to 0800 UTC for 652 the (a) URBAN and (b) DESERT experiment. (c) TWC differences [mm] (URBAN minus 653 DESERT) and (d) Relative differences [\%]. The Jeddah area is indicated by black lines. 654 The differences averaged over Jeddah are $2.06 \mathrm{~mm}$ or $4.25 \%$. 

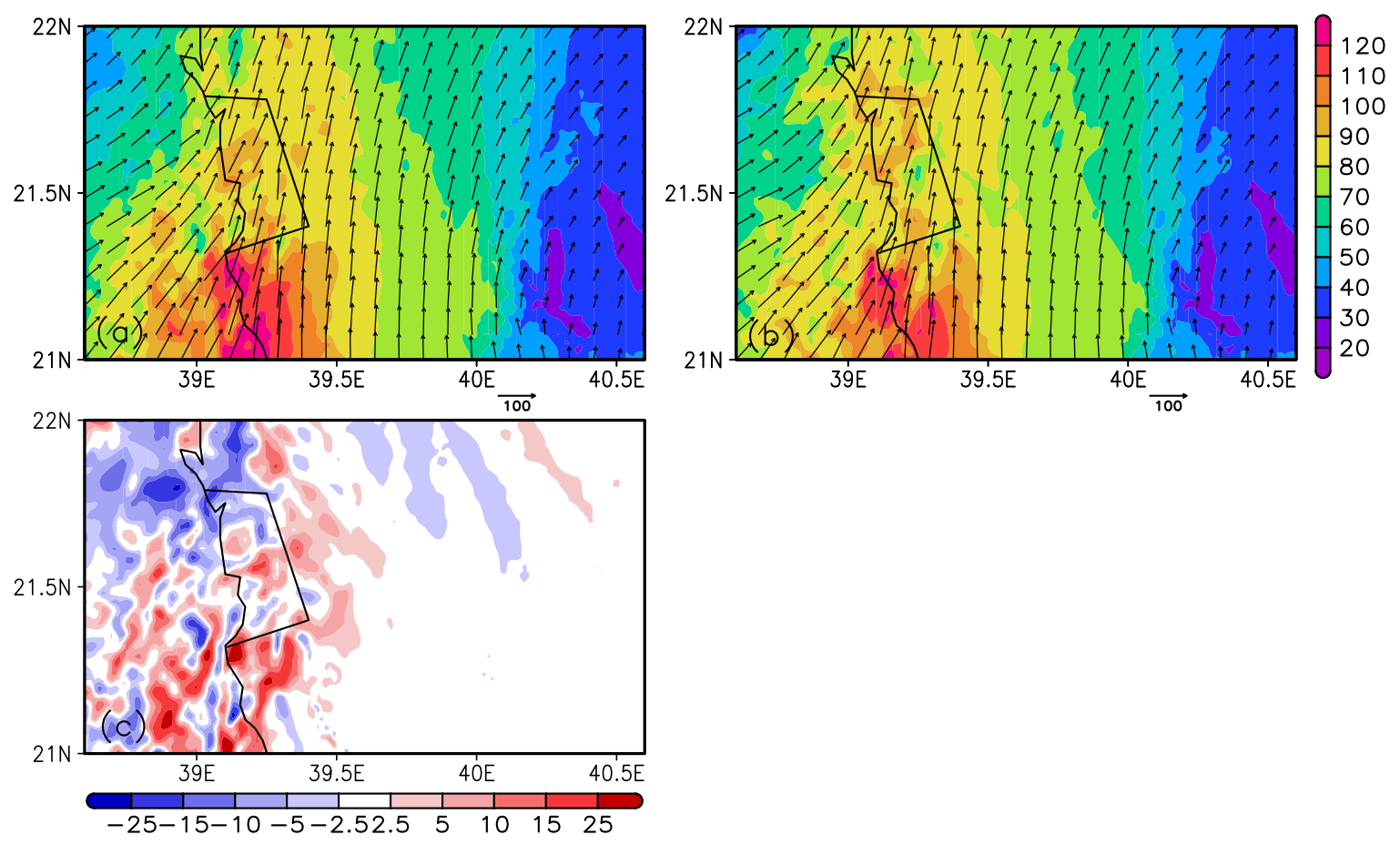

656 Figure 9: Vertically integrated horizontal water vapor fluxes (IVF) $\left[\mathrm{kg} \mathrm{m}^{-1} \mathrm{~s}^{-1}\right]$ averaged 657 from 0000 UTC to 0800 UTC for the (a) URBAN and (b) DESERT experiment. (c) IVF 658 differences $\left[\mathrm{kg} \mathrm{m}^{-1} \mathrm{~s}^{-1}\right.$ ] (URBAN minus DESERT). The Jeddah area is indicated by the 659 black lines. 

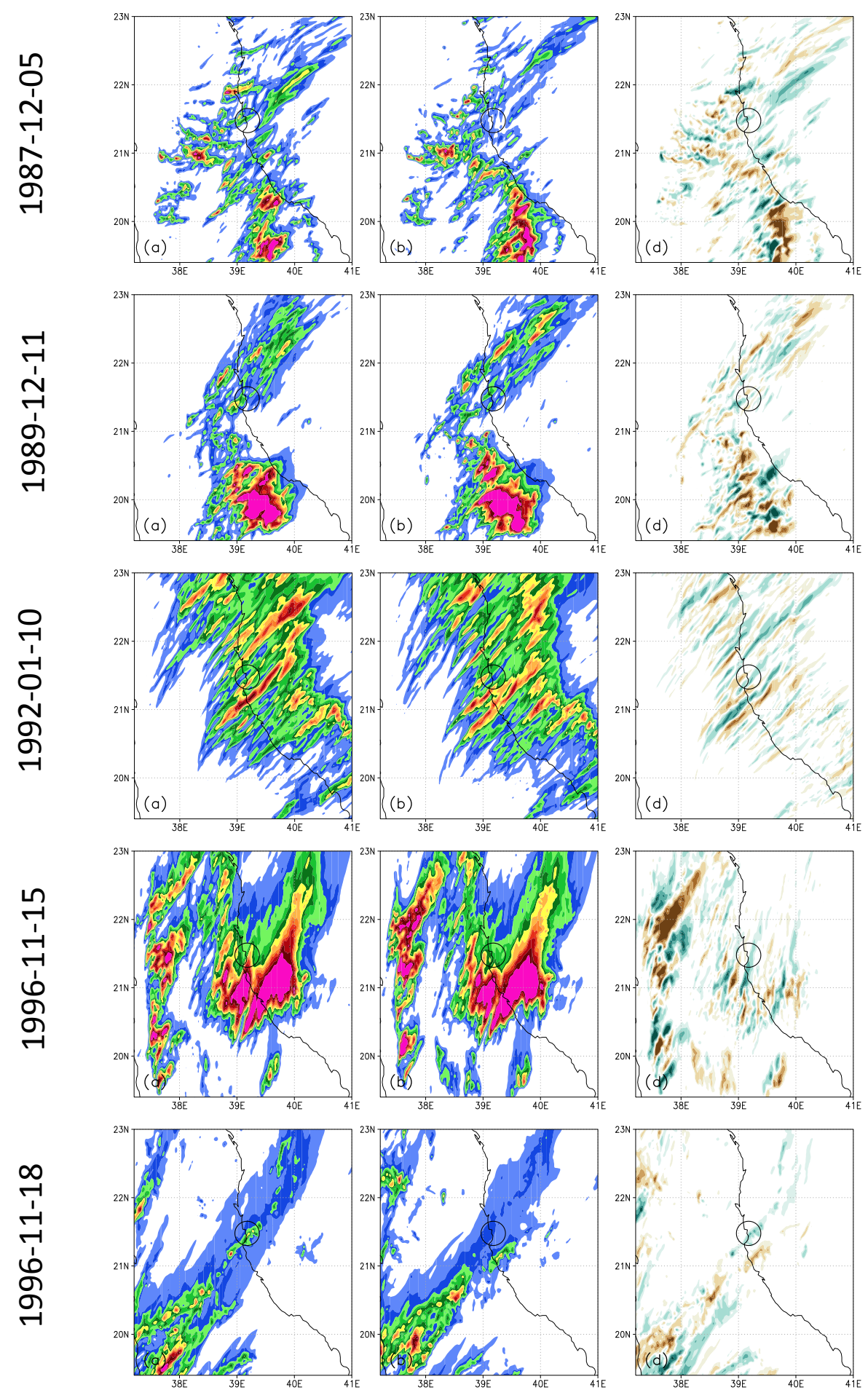

660

(a) URBAN

(b) DESERT

(c) $\Delta=($ a) - (b)

661 Figure 10: Simulated $24 \mathrm{~h}$ accumulated rainfall $\left[\mathrm{mm} \mathrm{day}^{-1}\right]$ of 10 extreme events from the 662 two experiments (a) Urban and (b) Desert, and (c) Rainfall differences (URBAN minus 663 DESERT). The Jeddah city area is circled. Event dates are denoted on the left of each rows. 

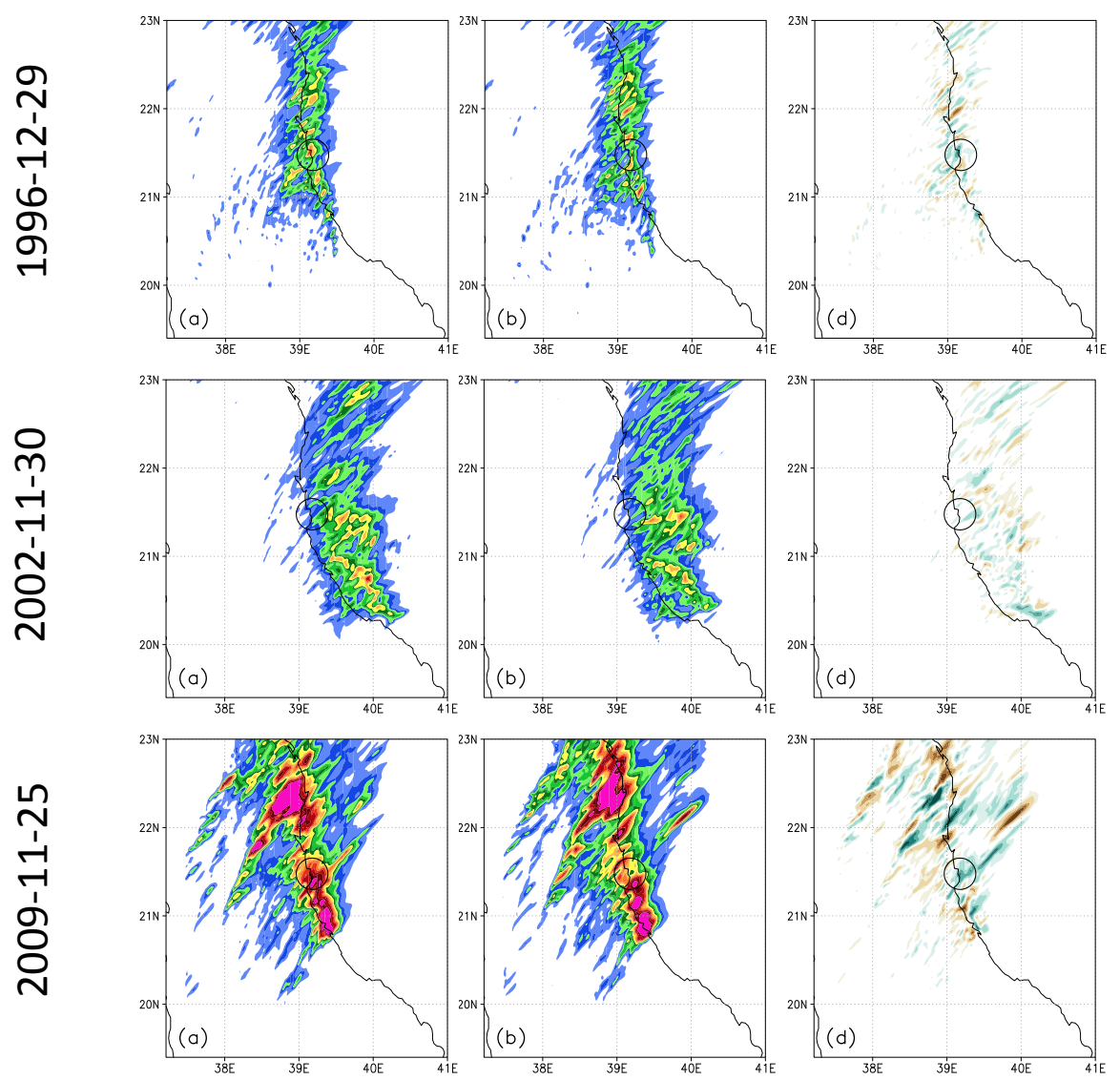

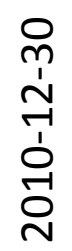
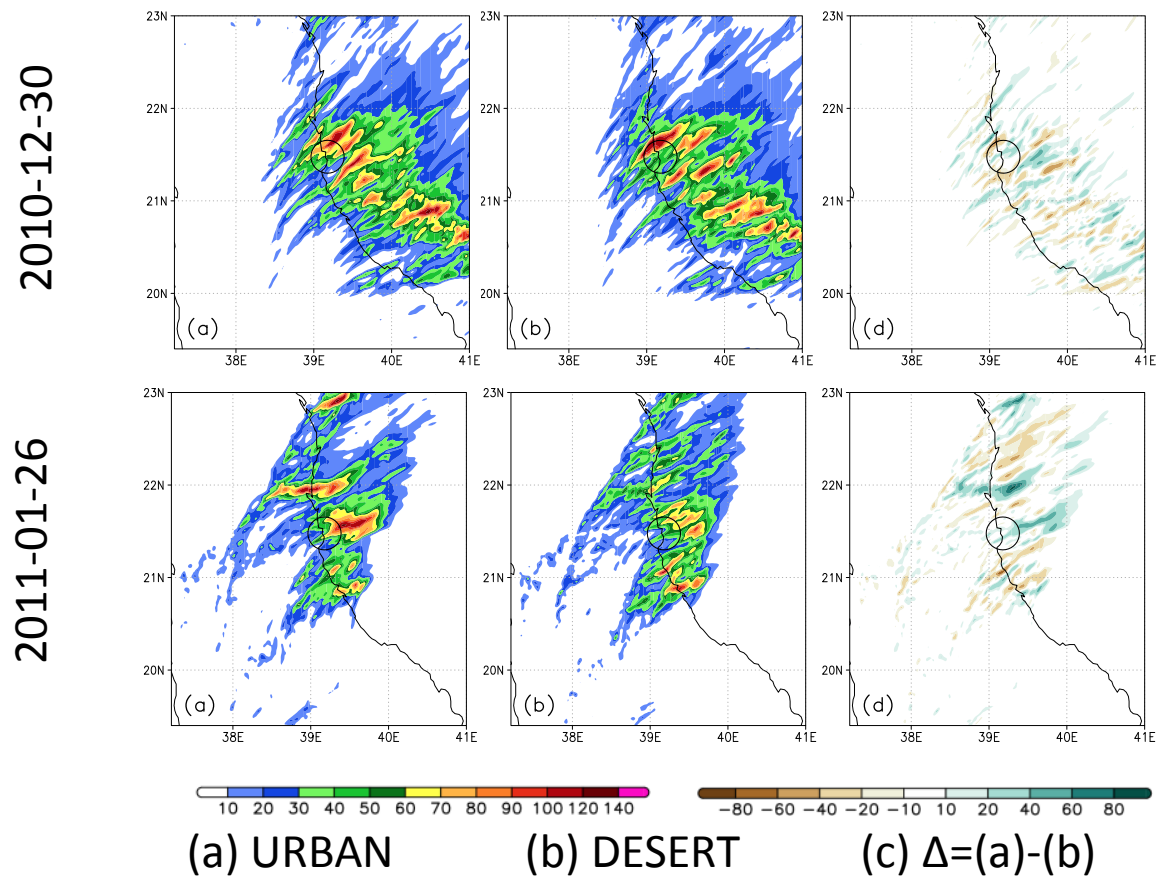

664

665

Figure 10: continued. 

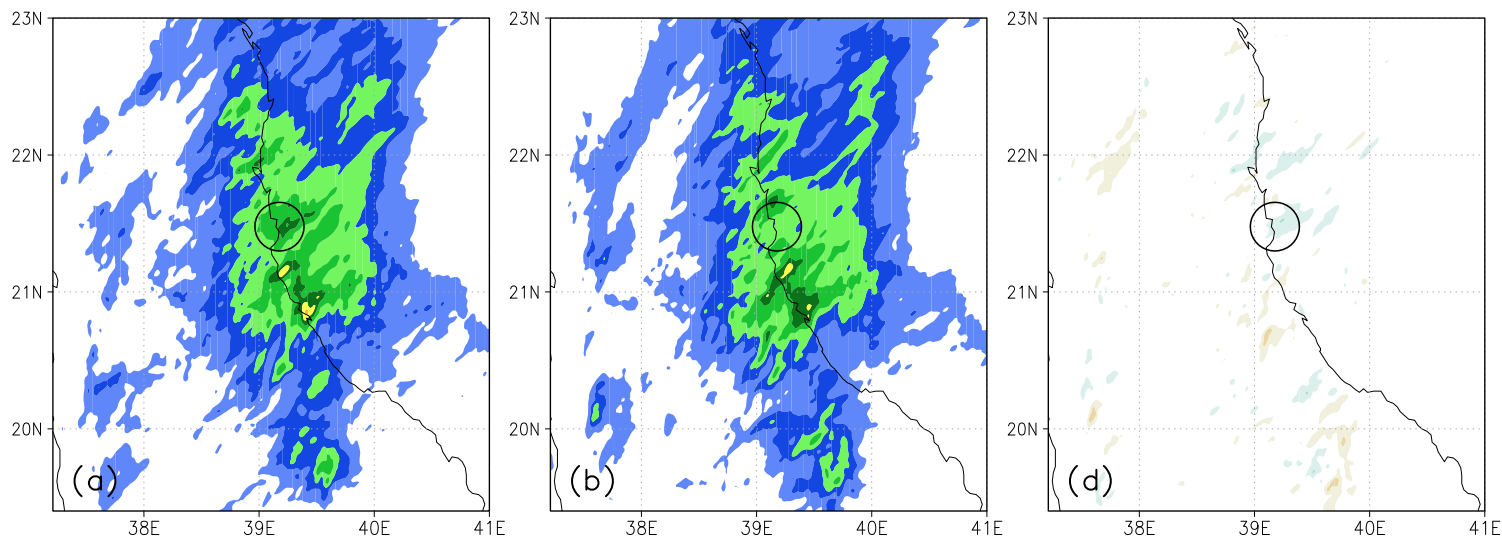

$-80-60-40-20-10 \quad 10 \quad 20 \quad 40 \quad 60 \quad 80$

(c) $\Delta=(\mathrm{a})-(\mathrm{b})$

673 Figure 11: The mean simulated $24 \mathrm{~h}$ accumulated rainfall [ $\left.\mathrm{mm} \mathrm{day}^{-1}\right]$ of 10 extreme events 674 from the two experiments (a) Urban and (b) Desert, and (c) Rainfall differences (URBAN 675 minus DESERT). The Jeddah city area is circled. 


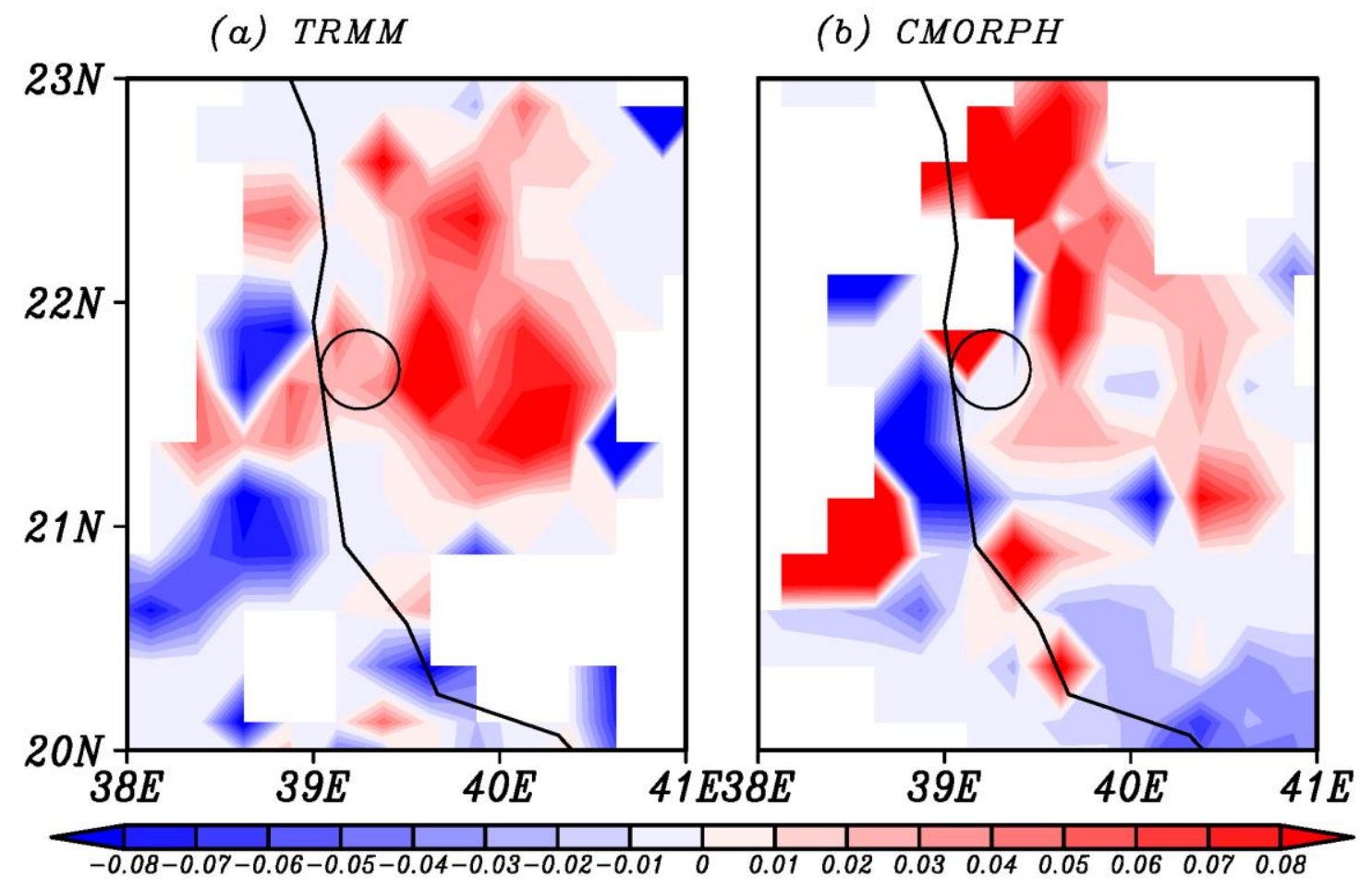

676

677

678

679

680

Figure 12: Trend of winter precipitation $\left[\mathrm{mm} \mathrm{year}^{-1}\right]$ associated with rainfall days heavier than $30 \mathrm{~mm} \mathrm{day}^{-1}$ in the past 3 decades over Jeddah from (a) TRMM and (b) CMORPH. The values over 0.02 and under -0.02 are statistically significant (at $90 \%$ confident level using Student t-test). The Jeddah city area is circled. 


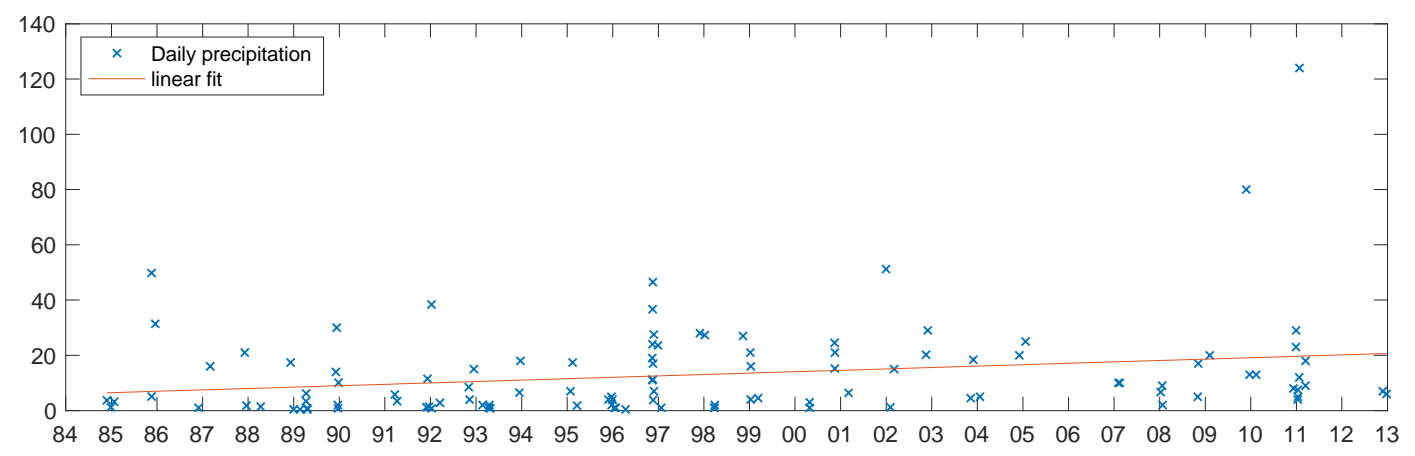

681

682 Figure 13: Jeddah station daily precipitation [mm] from 1984 to 2013. The $\mathrm{x}$-axis displays 683 the year. The trend of 3-decade period is $+0.51\left[\mathrm{~mm} \mathrm{year}^{-1}\right]$. 


\section{Tables}

Table 1. Rainfall [mm], surface temperature [K], sensible heat flux [W m-2], latent heat flux [W m-2], PBL height [m], and TCW $[\mathrm{mm}]$ of 10 extreme events averaged over Jeddah from the two experiments Urban and Desert, and the changes (URBAN minus DESERT). Rainfall changes are display in percentage. The first row of rainfall is from Jeddah station daily records.

\begin{tabular}{|c|c|c|c|c|c|c|c|c|c|c|c|c|}
\hline \multicolumn{2}{|c|}{ Date } & 1987- & 1989- & 1992- & 1996- & 1996- & 1996- & 2002- & 2009- & 2010- & 2011- & Mean \\
\hline \multirow{4}{*}{$\begin{array}{c}\text { Rainfall } \\
\text { [mm] }\end{array}$} & Station & 21.0 & 30.0 & 38.4 & 24.0 & 46.5 & 23.6 & 29.0 & 80.0 & 29.0 & 124.0 & 44.6 \\
\hline & URBAN & 18.75 & 24.05 & 45.19 & 54.81 & 34.46 & 41.32 & 32.77 & 93.45 & 62.60 & 54.45 & 46.2 \\
\hline & DESERT & 11.57 & 20.86 & 37.68 & 42.16 & 19.56 & 35.80 & 24.73 & 71.83 & 57.72 & 45.72 & 36.8 \\
\hline & Changes & $62 \%$ & $15 \%$ & $20 \%$ & $30 \%$ & $76 \%$ & $15 \%$ & $33 \%$ & $30 \%$ & $8 \%$ & $19 \%$ & $26 \%$ \\
\hline \multirow{3}{*}{$\begin{array}{c}\text { Surface } \\
\text { temperature } \\
{[\mathrm{K}]}\end{array}$} & URBAN & 297.0 & 295.5 & 293.4 & 295.8 & 297.7 & 295.0 & 297.7 & 297.1 & 295.7 & 294.4 & 295.9 \\
\hline & DESERT & 296.9 & 295.2 & 292.6 & 295.2 & 297.5 & 294.5 & 297.4 & 296.6 & 295.3 & 294.4 & 295.6 \\
\hline & Changes & 0.07 & 0.25 & 0.77 & 0.59 & 0.24 & 0.59 & 0.29 & 0.45 & 0.39 & 0.01 & 0.36 \\
\hline \multirow{3}{*}{ 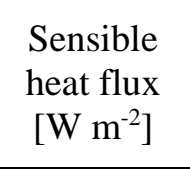 } & URBAN & -1.7 & -1.4 & -9.7 & -9.5 & -19.3 & -17.2 & -17.4 & -11.9 & -21.7 & -16.2 & -12.6 \\
\hline & DESERT & -4.3 & -1.5 & -11.6 & -13.0 & -24.1 & -19.6 & -20.8 & -13.8 & -24.6 & -17.1 & -15.0 \\
\hline & Changes & 2.6 & 0.1 & 1.9 & 3.4 & 4.8 & 2.4 & 3.4 & 1.8 & 2.9 & 0.9 & 2.4 \\
\hline \multirow{3}{*}{$\begin{array}{l}\text { Latent heat } \\
\text { flux [W } \mathrm{m}^{-} \\
\left.{ }^{2}\right]\end{array}$} & URBAN & 0.2 & -0.4 & -0.7 & 0.7 & 3.3 & -0.1 & 0.3 & 0.4 & 0.1 & -0.1 & 0.4 \\
\hline & DESERT & 0.4 & 0.0 & -0.4 & 1.4 & 4.7 & 0.4 & 1.5 & 0.6 & 1.0 & 0.9 & 1.0 \\
\hline & Changes & -0.2 & -0.3 & -0.2 & -0.7 & -1.4 & -0.5 & -1.2 & -0.2 & -0.9 & -1.0 & -0.7 \\
\hline \multirow{3}{*}{$\begin{array}{l}\text { PBL height } \\
{[\mathrm{m}]}\end{array}$} & URBAN & 63.9 & 92.0 & 179.3 & 289.5 & 896.0 & 467.1 & 546.5 & 429.0 & 561.9 & 435.3 & 396.1 \\
\hline & DESERT & 59.4 & 76.8 & 94.4 & 257.0 & 775.6 & 351.7 & 507.2 & 305.6 & 464.0 & 301.8 & 319.4 \\
\hline & Changes & 4.5 & 15.2 & 84.9 & 32.5 & 120.4 & 115.4 & 39.3 & 123.4 & 97.9 & 133.5 & 76.7 \\
\hline \multirow{3}{*}{ TCW [mm] } & URBAN & 41.9 & 42.0 & 41.5 & 33.8 & 27.6 & 29.7 & 45.8 & 49.2 & 41.2 & 43.9 & 39.6 \\
\hline & DESERT & 39.8 & 40.3 & 40.2 & 33.2 & 27.3 & 29.4 & 44.9 & 47.1 & 40.0 & 41.7 & 38.4 \\
\hline & Changes & 2.06 & 1.69 & 1.26 & 0.60 & 0.30 & 0.32 & 0.92 & 2.06 & 1.21 & 2.14 & 1.26 \\
\hline
\end{tabular}


Table 2. The default urban parameters used in the UCM.

\begin{tabular}{|c|c|}
\hline Urban Parameters [Unit] & Value \\
\hline Roof level (building height) [ $\mathrm{m}$ ] & 7.5 \\
\hline Standard Deviation of roof height $[\mathrm{m}]$ & 3.0 \\
\hline Roof (i.e., building) width [ $\mathrm{m}$ ] & 9.4 \\
\hline Road width [ m ] & 9.4 \\
\hline $\begin{array}{l}\text { Coefficient modifying the Kanda approach to } \\
\text { computing surface layer exchange coefficients. }\end{array}$ & 1.29 \\
\hline Thickness of each roof layer [ $\mathrm{m}$ ] & $0.05,0.05,0.05,0.05$ \\
\hline Thickness of each building wall layer [ $\mathrm{m}$ ] & $0.05,0.05,0.05,0.05$ \\
\hline Thickness of each ground (road) layer [ $\mathrm{m}$ ] & $0.05,0.25,0.50,0.75$ \\
\hline Lower boundary condition for roof layer temperature & Zero-Flux \\
\hline Lower boundary condition for wall layer temperature & Zero-Flux \\
\hline Lower boundary condition for ground layer temperature & Zero-Flux \\
\hline Ch of Wall and Road & Empirical Form of Narita et al. (1997) \\
\hline Surface and Layer Temperatures & 4-layer model \\
\hline Anthropogenic heating & No \\
\hline Anthropogenic latent heat & No \\
\hline Oasis effect & Not active \\
\hline $\begin{array}{l}\text { Evaporation scheme for impervious surfaces (for roof, } \\
\text { wall, and road) }\end{array}$ & $\begin{array}{l}\text { Hypothesized evaporation during } \\
\text { large rainfall events (Original) }\end{array}$ \\
\hline $\begin{array}{l}\text { Urban irrigation scheme, for vegetation in urban area } \\
\text { and green roof }\end{array}$ & No irrigation \\
\hline Green roof & No \\
\hline $\begin{array}{l}\text { Fraction of the urban landscape which does not have } \\
\text { natural vegetation. [ Fraction ] }\end{array}$ & 0.9 \\
\hline Heat capacity of roof $\left[\mathrm{J} \mathrm{m}^{-3} \mathrm{~K}^{-1}\right]$ & $1.0 \times 10^{6}$ \\
\hline Heat capacity of building wall $\left[\mathrm{J} \mathrm{m}^{-3} \mathrm{~K}^{-1}\right]$ & $1.0 \times 10^{6}$ \\
\hline Heat capacity of ground (road) $\left[\mathrm{J} \mathrm{m}^{-3} \mathrm{~K}^{-1}\right]$ & $1.4 \times 10^{6}$ \\
\hline Thermal conductivity of roof $\left[\mathrm{J} \mathrm{m}^{-1} \mathrm{~s}^{-1} \mathrm{~K}^{-1}\right]$ & 0.67 \\
\hline Thermal conductivity of building wall $\left[\mathrm{J} \mathrm{m}^{-1} \mathrm{~s}^{-1} \mathrm{~K}^{-1}\right]$ & 0.67 \\
\hline Thermal conductivity of ground (road) $\left[\mathrm{J} \mathrm{m}^{-1} \mathrm{~s}^{-1} \mathrm{~K}^{-1}\right]$ & 0.4004 \\
\hline Surface albedo of roof [ fraction ] & 0.2 \\
\hline Surface albedo of building wall [ fraction ] & 0.2 \\
\hline Surface albedo of ground (road) [ fraction ] & 0.2 \\
\hline Surface emissivity of roof [ - ] & 0.9 \\
\hline Surface emissivity of building wall [ - ] & 0.9 \\
\hline Surface emissivity of ground (road) [ - ] & 0.95 \\
\hline Lower boundary condition for roof temperature [ $\mathrm{K}$ ] & 293.0 \\
\hline $\begin{array}{l}\text { Lower boundary temperature for building wall } \\
\text { temperature }[\mathrm{K}]\end{array}$ & 293.0 \\
\hline $\begin{array}{l}\text { Lower boundary temperature for ground (road) } \\
\text { temperature }[\mathrm{K}]\end{array}$ & 293.0 \\
\hline
\end{tabular}

